\title{
Proportionated Distributions in Spatiotemporal Structure of the World Cultural Heritage Sites: Analysis and Countermeasures
}

\author{
Ya Yao ${ }^{1,2,3, *}$, Xinyuan Wang ${ }^{1,2,3, *}$, Linlin Lu ${ }^{1,2,3}\left(\mathbb{D}\right.$, Chuansheng Liu ${ }^{1,2,3}$, Qiang Wu ${ }^{1,4}\left(\mathbb{D}\right.$, Hongge Ren ${ }^{1,4}$, \\ Shu Yang ${ }^{1,4} \mathbb{D}_{\text {, Ruiqi Sun }}{ }^{1,4}$, Lei Luo ${ }^{1,2,3}$ and Kai $W_{u}{ }^{1,4}$
}

1 Aerospace Information Research Institute, Chinese Academy of Sciences, Beijing 100094, China; lull@radi.ac.cn (L.L.); liucs@radi.ac.cn (C.L.); wuqiang@radi.ac.cn (Q.W.); renhg@aircas.ac.cn (H.R.); yangshu20@mails.ucas.ac.cn (S.Y.); sunruiqi19@mails.ucas.ac.cn (R.S.); luolei@radi.ac.cn (L.L.); scwukai1@gmail.com (K.W.)

2 International Centre on Space Technologies for Natural and Cultural Heritage (HIST) under the Auspices of UNESCO, Beijing 100094, China

3 Key Laboratory of Digital Earth Science, Aerospace Information Research Institute, Chinese Academy of Sciences, Beijing 100094, China

4 College of Resources and Environment, University of Chinese Academy of Sciences, Beijing 100049, China

* Correspondence: yaoya@radi.ac.cn (Y.Y.); wangxy@radi.ac.cn (X.W.); Tel.: +86-010-8217-8197 (Y.Y. \& X.W.)

check for updates

Citation: Yao, Y.; Wang, X.; Lu, L.; Liu, C.; Wu, Q.; Ren, H.; Yang, S.; Sun, R.; Luo, L.; Wu, K. Proportionated Distributions in Spatiotemporal Structure of the World Cultural Heritage Sites: Analysis and Countermeasures. Sustainability 2021, 13, 2148. https://doi.org/10.3390/ su13042148

Academic Editor: Asterios Bakolas

Received: 4 January 2021

Accepted: 12 February 2021

Published: 17 February 2021

Publisher's Note: MDPI stays neutral with regard to jurisdictional claims in published maps and institutional affiliations.

Copyright: (c) 2021 by the authors. Licensee MDPI, Basel, Switzerland. This article is an open access article distributed under the terms and conditions of the Creative Commons Attribution (CC BY) license (https:/ / creativecommons.org/licenses/by/ $4.0 /)$.

\begin{abstract}
Asia, Europe, and Africa, connected by the maritime silk road (MSR) and the land silk road (LSR), as the cradle of ancient civilizations, contain rich cultural heritage resources. While aiming to achieve differentiated and targeted application, protection, and development of world cultural heritage (WCHS), it is essential to identify the temporal-spatial distribution features of WCHS on these three continents. For these WCHS elements, based on big earth data, we semi-quantitatively describe the features of spatial-temporal distribution, material types, civilization and religion characters, capital investment capacity, and risks by data cleaning, spatial analysis, and risk assessment. Our findings reveal features in these WCHS elements, including temporal and spatial distribution, the amount of different ancient civilizations and cultural diversity, and the need for preservation and funding capacity. Finally, this study's results indicate that we should take full advantage of the potential of cultural heritage, digital technologies, and the scientific protection of cultural heritage along with the MSR and LSR. Moreover, declarations of heritage in Africa and Central Asia should be extended to realize the precise "poverty alleviation" of WCHS protection in these regions. For further planning of WCHS sites along the Silk Road, we propose countermeasures to protect the global cultural heritage in the future and also provide theoretical guidance and specific scientific implementation directions to "strengthen efforts to protect and safeguard the world's cultural and natural heritage," as proposed by the United Nations.
\end{abstract}

Keywords: world cultural heritage site (WCHS); big earth data; space information technology; spatial-temporal distribution; imbalance; countermeasures

\section{Introduction}

In 1972, UNESCO established the World Heritage Committee, which aims to "protect the heritage of outstanding universal value" [1], and which has since organized a comparison of various heritages of member countries that joined the "convention for the Protection of the World Cultural and Natural Heritage." In addition, the Committee has added eligible heritage items to the UNESCO World Heritage List and listed others as a part of world heritage (WH). As of 2019, a total of 1133 cultural heritage, natural heritage, and mixed cultural and natural heritage items are included on the World Heritage List. The maritime silk road (MSR) and the land silk road (LSR) involve three continents-Asia, Europe, and Africa-and the adjacent sea areas. It is an open-space road network system with 766 cultural heritage items involved. Undisputedly, cultural heritage needs to be 
conserved, protected, and preserved. According to sustainable development goal (SDG) 11.4, the UN proposed to "strengthen efforts to protect and safeguard the world's cultural and natural heritage," and introduced, in 11.4.1, the "Total expenditure (public and private) per capita spent on the preservation, protection and conservation of all cultural and natural heritage, by type of heritage (cultural, natural, mixed and World Heritage Centre designation), level of government (national, regional and local/municipal), type of expenditure (operating expenditure/investment) and type of private funding (donations in kind, private non-profit sector and sponsorship") index calculation method [2].

However, the availability of public budget in culture in general will vary between countries. Issues of compiling public and private finances could result in the underestimation of the value of total investment in culture. It is important to take into account national transfer funds among different levels of governmental (regional, state, municipal) to avoid double counting. An alternative could be to assess the public expenditure in culture. However, the Classification of the Functions of Government (COFOG) may not be detailed enough to identify only heritage [3]. From the perspective of improving the quantitative indicators of UNESCO, working through a comprehensive background knowledge of the world cultural heritage was needed.

In recent years, researchers have developed from the early qualitative characterization of WH spatial distribution to quantitative comparative research. Over decades, scholars have accumulated large amounts of data and developed distinct methods for investigating the WH spatial distribution, while also evaluating the risk of cultural heritage suffering from natural disasters in some circumstances. For example, several studies have addressed the risk of natural disasters such as sea-level rise, floods, earthquakes, and air pollution. In addition, the threats to world cultural heritage sites (WCHS) caused by the process of tourism and urbanization have also attracted the attention of many scholars [4-14]. Overall, extant studies typically focus on national-level and specific sites but rarely on a macro perspective. A macro-level research is of great significance likewise. On the one hand, it can overcome the excessive attention to the ruins at the national level, especially cross-national cultural routes such as the Routes Network of Chang'an-Tianshan Corridor was inscribed on the World Heritage. It is necessary to break through the international and multicultural heritage for a comprehensive observation of temporal and spatial characteristics. On the other hand, a continental-scale perspective can bring more systematic and comprehensive temporal and spatial distribution information and characteristic background. At the UNESCO level, there are more reference information to propose global regulations. At the level of a single heritage site, it is easy to find the similarities and differences with other cultural world heritage backgrounds, and provide clues for the exchange of experience in site management and protection.

Asia, Africa, and Europe-through which the MSR and LSR navigate-are rich in cultural resources. The number of cultural heritage sites, including mixed heritage sites, along the MSR and LSR is 776 accounts for $69.2 \%$ of the global total. At present, the temporal and spatial distribution characteristics of these WCHS sites along the MSR and LSR remain unclear. The lack of in-depth summary and understanding of background information can easily cause the management process and developing specific strategies to deviate from the original purpose. It is significant to interpret the distribution features of the WCHS sites in this area from a macro geographical perspective and to fill the gap in the macroscopic spatial and temporal distribution of this large area. Thus, our research aim is to provide relevant background information and countermeasure suggestions for managers to formulate proposals, regulations, and international cultural heritage protection experience exchanges through the analysis of the spatiotemporal structure, cultural characteristics, and risks assessment of the regional cultural heritage.

\section{Materials and Methods}

The MSR and LSR have undergone different evolution stages throughout history, while the routes have always bridged the cultures of Asia, Europe, and Africa. Thus, 
these regions were selected as the study area. The spatial scope, which is based on the statistics of 92 countries in Asia, Africa, and Europe, contains 766 WCHS sites, including 23 natural and cultural mixed sites as of December 2019.

\subsection{Materials}

Large-scale research has certain challenges. Among them, the availability of data, the rationality of various indicators under different backgrounds, and the applicability of methods all need to be considered.

This research aims to reveal the distribution characteristics and principles of cultural heritage along the MSR and LSR. Preliminary data were gathered from the official documentation of the 2019 World Heritage List from the UNESCO World Heritage Center and websites of cultural heritage sites along the LSR and MSR, including the UNESCO cultural heritage site application documentation.

The data sets used to evaluate the risks faced regarding WCHS sites include the 2019 Holocene volcano data from the Smithsonian Institution National Museum of Natural History Global Volcanism Program database [15]; the 2017 global landslide susceptibility data set, with a spatial resolution of $1 \mathrm{~km}$, from the global precipitation measurement (GPM) of the National Aeronautics and Space Administration (NASA) [16]; the global peak acceleration data on ground motion in 2015, with a spatial resolution of $10 \mathrm{~km}$, from the United Nations 2015 disaster mitigation assessment report data sharing platform [17]; the global human settlement layer (GHSL) in 2000 and 2015, with a spatial resolution of $250 \mathrm{~m}$ [18]; world population grid products (Worldpop) in 2000 and 2015, with a spatial resolution of $100 \mathrm{~m}$ [19]; global nightlight image data (DMSP/OLS) in 2000 and 2013, with a spatial resolution of $1 \mathrm{~km}$ [20]; gross domestic product (GDP) statistics from Asia, Europe, and Africa (from the International Monetary Fund) [21]; and Gaofen satellite images covering some WCHS sites.

\subsection{Methodology}

\subsubsection{Big Data Cleaning}

The WH text data were downloaded from the UNESCO World Heritage Center website, and the relevant records and materials on cultural heritage on the Internet were obtained utilizing web crawlers. After cleaning and screening the relevant high-frequency vocabulary, important attributes were added to the original data set to form a cultural heritage data set of the LSR and MSR.

\subsubsection{Statistical Analysis of Cultural Heritage}

The material of the cultural heritage, the type of agricultural production, the historical period, the cultural heritage evaluation standard, and the regional economic situation were analyzed. A spatial analysis of cultural heritage data was carried out using a GISbased approach.

\subsubsection{Risk Assessment of Cultural Heritage}

Since the 1990s, preventive protection of world cultural heritage has risen and been developed [22]. The risk management theory has gradually been introduced into the protection of world cultural heritage. It can move the implementation nodes of various heritage protection measures such as technology and management forward. Thereby, effectively reducing the destruction of cultural heritage caused by various factors. The risks that cultural heritage sites face were evaluated from two aspects: Natural and human influences.

For natural influences, we established a distance model to assess the distance between the WCHS site and the risk source to carry out a quantitative evaluation of the risk. When conducting the natural disaster risk assessment on cultural heritage, it is necessary to consider the universality of data, rather than specific geomorphology, climatic environment, etc. Among the four natural disasters of meteorology, ocean, biology, and geology, due to 
the wide distribution, highly destructive, and the large-scale data is of good quality and more accessible to researchers, we select the elements of geological disasters for evaluation.

For the volcanic hazard risk assessment, we built a distance model that determines the distance between active volcanoes and WCHS sites. Three ring-buffer zones to active volcanoes with different risk levels were defined (see Table 1). Then, we analyzed active volcanoes with a buffer zone of 20 and $40 \mathrm{~km}$, individually, and performed a spatial overlay analysis of the buffer analysis results with the vector boundary of the WCHS site to identify the risk level of volcanic disasters at WCHS sites.

Table 1. Volcanic risk level.

\begin{tabular}{cccc}
\hline Volcanic Risk Level & Low & Medium & High \\
\hline Buffer Distance & $>40 \mathrm{~km}$ & $20 \sim 40 \mathrm{~km}$ & $\leq 20 \mathrm{~km}$ \\
\hline
\end{tabular}

For the landslide disaster risk assessment, NASA established a global landslide model using multiple parameters, such as topography, geology, seismic activity, land use, and road traffic, and they developed a global landslide susceptibility data set that mainly describes the susceptibility of landslides on a global scale. According to the spatial analysis tools, the final susceptibility value (see Table 2) for the cultural heritage sites indicated the landslide risk level of the heritage site after data were extracted and analyzed.

Table 2. Landslide risk level.

\begin{tabular}{cccccc}
\hline Landslide Risk Level & Ultra-Low & Low & Medium & High & Ultra-High \\
\hline Susceptibility & 1 & 2 & 3 & 4 & 5 \\
\hline
\end{tabular}

Regarding the earthquake disaster risk assessment, earthquakes are random, devastating, and difficult to prepare for, which increases the vulnerability of cultural heritage sites. These seismic events can directly cause serious damage to the landscape structures or induce various primary and secondary geological disasters. At present, the peak ground acceleration (PGA) with a probability of exceeding $10 \%$ in 50 years is often used to measure the destructive magnitude of earthquake disasters. This index provides the basis for determining the seismic intensity and has been widely used in earthquake disaster prevention for buildings. With the support of the spatial extraction analysis tool, we superimposed the global seismic PGA data with the vector points of the WCHS sites. Finally, we obtained the seismic intensity value (see Table 3 ) of the sites and then further classified the earthquake risk level at WCHS sites.

Table 3. Earthquake risk level.

\begin{tabular}{cccccc}
\hline Earthquake Risk Level & Ultra-Low & Low & Medium & High & Ultra-High \\
\hline Seismic intensity & $<6$ & 6 & 7 & 8 & $\geq 9$ \\
PGA $/\left(\mathrm{cm} / \mathrm{s}^{2}\right)$ & $<39.2$ & $39.2-88.3$ & $88.3-186.4$ & $186.4 \sim 372.8$ & $\geq 372.8$ \\
\hline
\end{tabular}

In terms of human influence, there are many factors affecting the world cultural heritage caused by human activities. The main threats with negative risks include tourism, urbanization, war, looting, etc., but there are fewer quantifiable indicators. The impact of tourism on cultural heritage has always been a highly controversial hot topic, but due to the varying degrees of access of the data in the research area, it is difficult to achieve continental-scale research. The current role of remote sensing technology in the monitoring of heritage sites has attracted much attention from scholars [23-25]. The development of urbanization has changed the city's land coverage and utilization, transportation, landscape and environment, making world heritage sites facing direct or indirect damage caused by factors. The use of multi-source remote sensing data and products to establish an 
urbanization intensity index to monitor the dynamics of cities around cultural heritage sites provides a basis for the protection of world cultural heritage sites.

The urban development and the intensity of human activities around WCHS sites can be measured by the degree of development, utilization, and transformation of the natural surface coverage by human land-use activities. The expansion of urban construction land, increased light intensity, and increased population density can reflect the process of global urban development from different aspects [26]. Therefore, the global human settlements layer (GHSL) data, population grid data, and the brightness of lights at night representing urban construction land were selected and normalized to calculate the urbanization intensity index (UII) [27]. The urbanization intensity index serves as a new indicator for monitoring the dynamics of cities around cultural sites. Using this indicator to monitor the spatial distribution and change characteristics of the urbanization intensity around the heritage site is helpful to assess the sustainable development of the city, deepen the understanding of the local urbanization development and the relationship between man and land, and become a world heritage site. First, we selected the construction land data, population grid data, and night light data in the GHSL, and we performed preprocessing steps, such as calibration and projection conversion of the data. Next, we centered on the WCHS sites, set buffer zones at 500, 1000, 1500, 2000, 2500, and $3000 \mathrm{~m}$ away from the sites. Then, we calculated the average values of urban construction land, night light, and population density in each buffer zone to obtain three unique values for the three indicators. Overall, we planned to establish a UII reflecting the intensity of human activities for quantitative risk evaluation and its formula:

$$
\mathrm{UII}=\sqrt[3]{B U_{\text {nor }} \times N T L_{\text {nor }} \times P O P_{\text {nor }}}
$$

where $B U_{\text {nor }}, N T L_{n o r}, P O P_{n o r}$, respectively, represent the normalized urban construction area, night lighting, and population data.

Finally, the UII values of the buffer zones were averaged to obtain the UII value of the cultural sites. A greater UII value represents a higher level of urbanization and intensive human activities and vice versa. According to the spatial pattern and temporal changes of the impact of urban expansion on cultural heritage sites, the impact of urban expansion on cultural heritage sites was identified and evaluated.

\section{Results and Analysis}

\subsection{Spatial-Temporal Characteristics of Cultural Heritage Sites}

\subsubsection{Listed Time of WCHS Sites}

We collected statistics on the number of sites listed in WCHS every decade in Asia, Africa, and Europe individually (Figure 1). Intuitively, in the four-time periods, the number of European cultural heritage on the World Heritage List increased first and then decreased, while Asia was on a steady upward trend and may still have a certain upward potential. Africa is unstable and fluctuating, but compared to Eurasia, it had a small number during various periods, and the period of faster growth occurred in the first 10 years of the 21st century. Considering the historical origins of the African continent, its growth potential is greater. The number of three continents inscribed in the WCHS list in different time periods is affected by many factors, especially the geopolitics during World War II and the Cold War. There are differences in cultural identities and values between the East and the West. While the number of cultural heritages in Asia is rising is certainly owed to this evidence of persistent transnational efforts to disarm fears stemming from war, empire, racism, and ignorance during this era of intense struggle and redefinition [28]. 


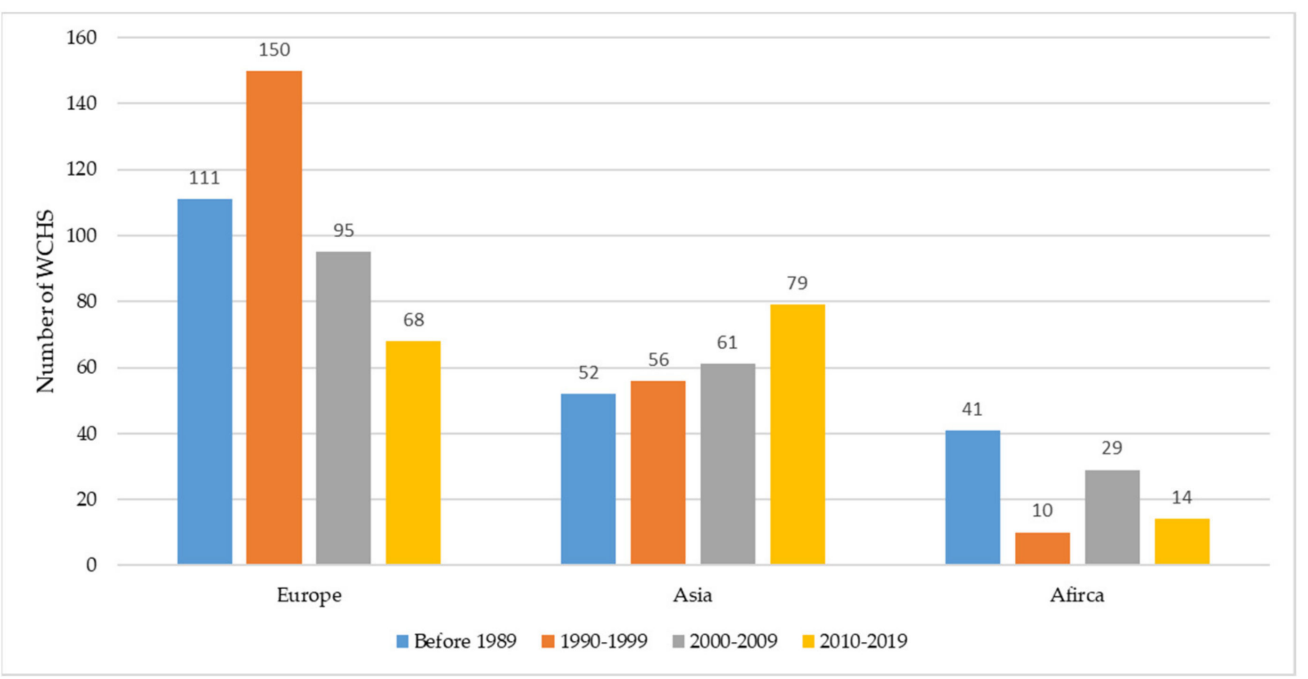

Figure 1. The number of sites on world cultural heritage sites (WCHS) in every decade, 1973-2019.

\subsubsection{Chronological Features of WCHS Sites}

The age of cultural heritage is straightforwardly related to the cultural background and characteristics it reflects. Specifically, the start time of cultural heritage represents the emergence of that civilization or cultural phenomenon, which is of great significance for the individual to interpret the cultural connotation.

Figure 2 shows the chronological distribution of cultural and mixed heritage sites in Asia, Europe, and Africa. The amount of historical information carried by the cultural heritage of different materials varied, so it has natural advantages in the transmission of cultural information. Generally speaking, the older the age, the larger the natural erosion and destruction by human activities become, and the lower the number of cultural and mixed heritage sites. Overall, the number of cultural and mixed heritage sites decreases with age. The peak age of the number of cultural and mixed heritage sites reflects the relative peak period of the development of human civilization. From the 11th to 19th century, as the peak area of the number of WCHS sites and mixed heritage sites, we can see the great changes of human beings from the end of the Middle Ages to the Renaissance, the Industrial Revolution, and the important development period of China in Song, Yuan, Ming, and Qing dynasties. The highest peak of this stage is the High Renaissance in the 15th and 16th centuries. Another peak is the 8th century BCE to the 2nd century CE. In this period, Confucianism, Buddhism, and Christianity, which appeared relatively independently in China, India, and Palestine at the same time in Europe, Asia, and Africa, emerged and still have a great influence today. This period contains both ancient Rome and the Han Empire, forming a peak of the Silk Road heritage. Other short-lived peaks in the 20th century BCE and the 30th century BCE also correspond to relevant ancient civilizations. However, due to the large time-span of the New Paleolithic Age, the large number of heritage sites does not mean that the heritage resources of the ancient era are sufficient. 


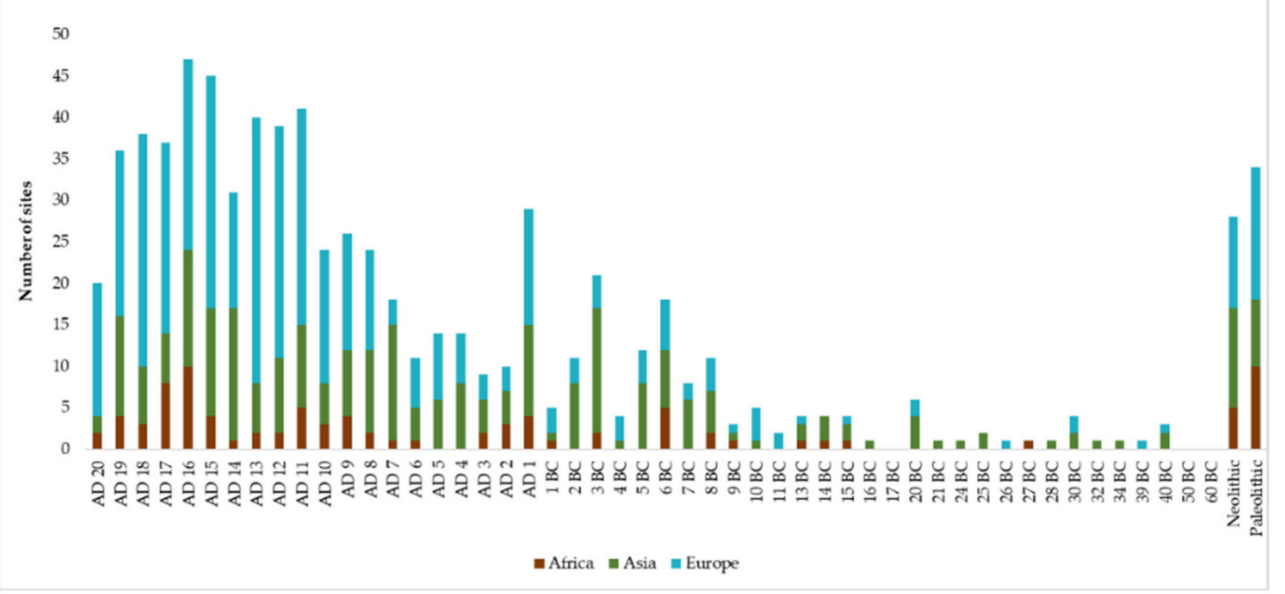

Figure 2. Chronological distribution of cultural and mixed heritage sites in Asia, Europe, and Africa.

Figure 2 also illustrates that the period distribution of cultural heritage in Asia is the most uniform and the most concentrated is in Europe. The highest peak in Asia appeared in the 3rd century BCE, mainly in China, India, and Sasanian Empire Central Asia. During this period, Northeast Asia completed the leap from the Bronze to the Iron Age, with improved productivity, spiritual beliefs, and the early Silk Road sprouted during this period. The peak of Africa appeared in the Paleolithic period, and in the 16th century, Paleolithic Africa was related to human origins, and many sites related to human origins were discovered. The 16th century was also the time of African colonial rule. During the peak period, the old traditional cultures are broken in the African continent. The African continent show colonial cultural history, rather than the reaction of the local native historical and cultural states. The peak period in Europe appeared in the 13th century halfway through the Middle Ages, the heyday of the European feudal era and the budding stage of the Renaissance.

With the marketization of world cultural heritage, WCHS has been used as a cultural symbol to promote the communication and interaction of people from different cultures [29]. Although the age of WCHS cannot directly and completely reveal the development trajectory of world civilization, sites with OUVs in important stages of human history deserve to be protected and respected, to show world history and culture more comprehensively. From the perspective of the historical time scale of WCHS, the protection of WCHS should entail the excavation, application, and maintenance of the more ancient cultural heritage sites, while strengthening the research on cultural heritage that can illuminate the major cultural topics of human history.

\subsubsection{Spatial Characteristics of Cultural Heritage Sites}

A spatial distribution map (Figure 3) of the cultural heritage sites in the LSR and MSR region indicates that cultural heritage sites are unevenly distributed in the three continents. Overall, the spatial distribution of cultural heritage features a patchy distribution. East Asia, Europe, and Africa are relatively dense along the Nile. There are many cultural heritage sites along the MSR and LSR. The number of cultural heritage sites is the largest in Western Asia/Europe on the western part of the Silk Road, North Africa, and the Mediterranean areas, most of which belonged to ancient Greek and Roman culture with a long history. Some sites belonged to Arabs and the ancient Egyptians in the agricultural area. During the period after the Middle Ages in Europe, a large Christian cultural heritage was created. In ancient China in East Asia and ancient India in South Asia, many cultural heritage sites reflect the long history of their civilizations. Some sites in the agricultural area belonged to other cultures, such as the Arab and ancient Egyptian cultures. The relatively mild climate conditions and sufficient light and heat promoted commercial agriculture, animal husbandry, and gardening. The development of karma promoted the prosperity of 
civilizations such as Greece and Rome. Additionally, under the influence of the Industrial Revolution, the Renaissance, and the Enlightenment, Christian culture flourished in most parts of Europe, and there were more Christian cultural heritage sites created in the Middle Ages and beyond. In addition, the long-standing human civilizations in ancient China in East Asia and ancient India in South Asia gave birth to many cultural heritage sites.

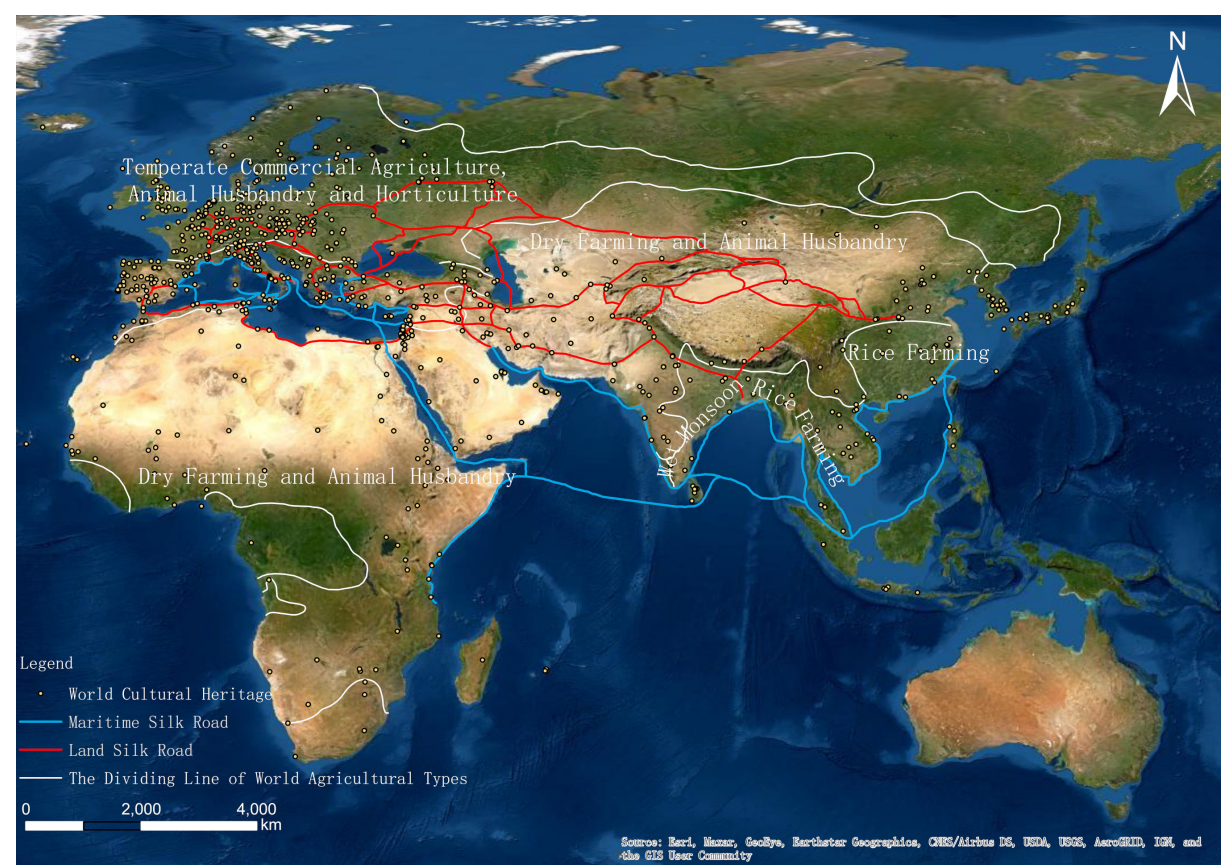

Figure 3. Spatial distribution map of the cultural heritage sites according to the different types of agriculture.

\subsection{Spatial Distribution of Material Types in Cultural Heritage Sites}

As a carrier of historical culture, material types of cultural heritage are complex and diverse. The material is not only directly related to the current preservation status of cultural heritage, but also vital to the subsequent technical application of protection and conservation. Under the established UNESCO cultural heritage classification reference standards criteria, we categorized the materials used by the main body of the building group into cultural relics, relics, and cultural landscape types: Soil, stone, wood, earth and stone, earth wood, wood and stone, iron, and comprehensive types of more than three materials. Among them, the main materials at the heritage sites include three or more, typically earth, wood, stone, and iron materials, which constitute mixed materials. Since masonry and stone structures are not easily distinguished in many buildings, they were all classified as stone. The statistics of the classification results by different material types in the WCHS of the LSR and MSR are shown in Table 4.

Table 4. Statistics on the frequency and ratio of different material types in WCHS.

\begin{tabular}{ccccccccc}
\hline $\begin{array}{c}\text { Material } \\
\text { Type }\end{array}$ & $\begin{array}{c}\text { Wooden } \\
\text { Heritage }\end{array}$ & $\begin{array}{c}\text { Earthen } \\
\text { Heritage }\end{array}$ & $\begin{array}{c}\text { Stone and } \\
\text { Brick Heritage }\end{array}$ & $\begin{array}{c}\text { Stone- } \\
\text { Earthen } \\
\text { Heritage }\end{array}$ & $\begin{array}{c}\text { Stone- } \\
\text { Wooden } \\
\text { Heritage }\end{array}$ & $\begin{array}{c}\text { Wood- } \\
\text { Earthen } \\
\text { Heritage }\end{array}$ & $\begin{array}{c}\text { Steel } \\
\text { Heritage }\end{array}$ & MixedHeritage \\
\hline $\begin{array}{c}\text { Frequency } \\
\text { Ratio }\end{array}$ & 21 & 51 & 441 & 185 & 31 & 8 & 9 & 20 \\
\hline
\end{tabular}


According to Figure 4, stone and brick ranked first (57.6\%) in all heritage sites. Adding stone-earthen heritage materials brings this figure to more than $80 \%$. This finding reflects the distinct characteristics that stone and brick materials are most likely to endure, whereas earthen and wood heritages are susceptible to natural processes of decay, making preservation difficult. Thus, for earthen and wood heritage materials, protection methods are more vital than other factors, such as management and urbanization. Figure 4 shows that stone and brick heritage materials are all ranked in the first place, while the stone-earthen heritage materials follow behind in Asia, Africa, and Europe. The amount of historical information carried by the cultural heritage of different materials varied, so it has natural advantages in the transmission of cultural information. This finding suggests that these two types are better maintained regardless of geographical diversity and architectural awareness in both the East and the West. The quantity and proportion of stone and brick heritage materials in Europe are much higher than in Asia and Africa. This phenomenon is presumably directly related to the availability of natural resources in individual regions and religious architectural awareness.

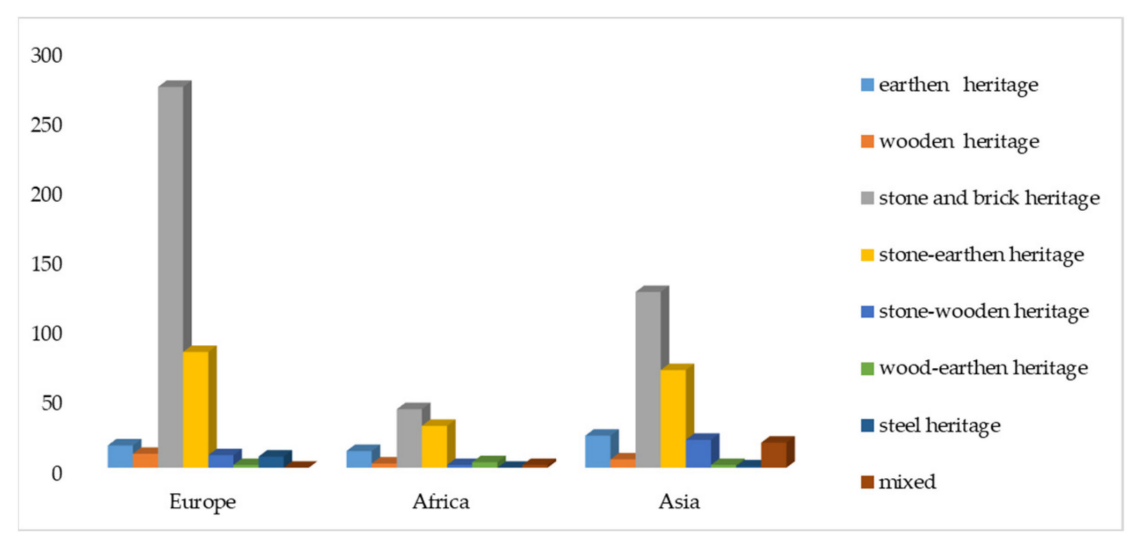

Figure 4. The distribution of different materials at WCHS sites in Asia, Europe, and Africa.

\subsection{Civilization Inheritance Characteristics of Cultural Heritage Sites}

Cultural diversity is a new concept that has frequently appeared in various documents and strategic plans of UNESCO in recent years [30]. Through the World Heritage Committee and its subordinate World Heritage Center and other institutions, it has gradually appeared in the context of cultural heritage protection. It is closely related to the new trends in the field of world heritage protection in recent years. Therefore, clarifying the Civilization Inheritance Characteristics of Cultural Heritage Sites has an impact on the world heritage system that will help us deepen the field of world heritage protection. Understanding the important direction and hot issues of its development is beneficial to the development of cultural heritage protection.

Civilization and cultural value are the core connotations of WCHS. The qualitative classification of civilization and cultural types, as well as the collection of quantitative statistics to discover the temporal and spatial distribution of WCHS, is of great significance for the protection, development, and utilization of the outstanding universal value of WCHS. The universal cultural connotation of WCHS is rich. We used statistics on several major civilization systems to observe the spatial laws and significance of the cultural connotations of WCHS. Table 5 displays the proportions of the four cradles of civilization in the total heritage. It is clear that, among the four cradles of civilization, the Chinese civilization has the most cultural heritage sites due to its own continuous culture. What should be noted is that the amount of prehistoric civilization heritage is $20 \%$ more than the total amount of the four primary archaic civilizations heritage. Despite its large time-span, this fact may be due to the fact that stone and brick and stone-earthen martial heritage materials account for $73 \%$ of prehistoric sites, such as cave sites and rock paintings, which are durable. By analyzing the spatial distribution of the top three civilizations with the largest number of cultural her- 
itage sites, we found that the ancient Roman civilization has the largest number of heritage sites, which are densely distributed along the Mediterranean. Although the number of Arab cultural heritage sites is the smallest, its distribution is the most extensive, spanning the largest latitude and longitude in Asia, Europe, and Africa. The radiation of Chinese civilization is the most intense, mainly around East Asia, which is also the dominant area of its cultural influence.

Table 5. Statistics of four cradles of civilization and prehistoric civilization in WCHS.

\begin{tabular}{cccccc}
\hline $\begin{array}{c}\text { Civilization } \\
\text { Type }\end{array}$ & $\begin{array}{c}\text { Prehistory } \\
\text { Civilization }\end{array}$ & $\begin{array}{c}\text { Chinese } \\
\text { Civilization }\end{array}$ & $\begin{array}{c}\text { Indus Valley } \\
\text { Civilization }\end{array}$ & $\begin{array}{c}\text { Mesopotamian } \\
\text { Civilization }\end{array}$ & $\begin{array}{c}\text { Ancient } \\
\text { Egyptian } \\
\text { Civilization }\end{array}$ \\
\hline $\begin{array}{c}\text { Frequency } \\
\text { Ratio }\end{array}$ & 72 & 41 & 6 & 6 & 6 \\
\hline
\end{tabular}

Religion, as an important cultural element, is a vital indicator for distinguishing people, and it is also a significant factor affecting the cultural landscape. In contrast, religion has a greater influence than language, and many cultural landscapes in the world are products of religion. The formation of many WCHS sites has been promoted by religion, thus shaping unique religious and cultural landscapes. As Lewis Mumford [31] pointed out, "the city originally appeared as a holy place." Religion, as an important ideology of mankind, gathers a large population tightly around religious buildings to facilitate daily sacrifices, prayers, and other activities. Among the 766 WCHS sites along the LSR and MSR, the number of cultural heritage sites with obvious confirmed religious significance is 487. The religious distribution ratio of the WCHS of the religions involved is shown in Figure 5a. In terms of spatial distribution, the highest proportion of Christianity is mainly concentrated in the European region, accounting for $81.9 \%$ of Christian cultural heritage. The rest are scattered in West Asia and North Africa adjacent to the European region. The Islamic cultural heritage is mainly distributed in Asia (56.4\%). The spatial distribution (Figure 6) indicates that, among the religious WCHS sites, Christianity has the largest number and the most concentrated space. Compared with that evenly distributed space, Islamism has a wider radiation range, while Buddhist and Hindu heritages are more concentrated in specific areas. The religious development process is closely related to the political and military connection and its own transmission methods.

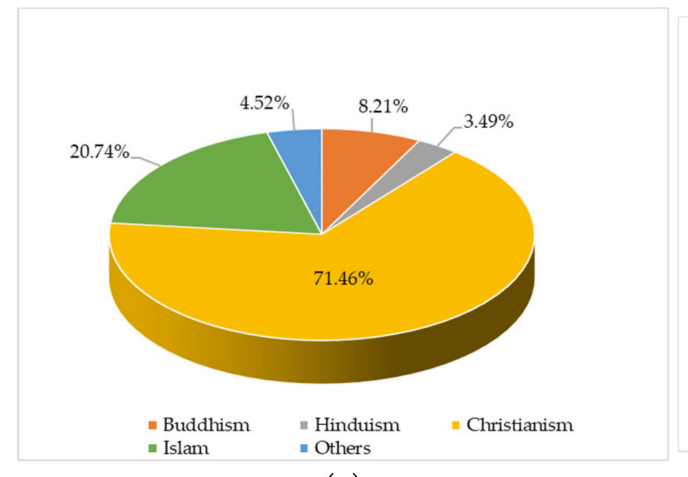

(a)

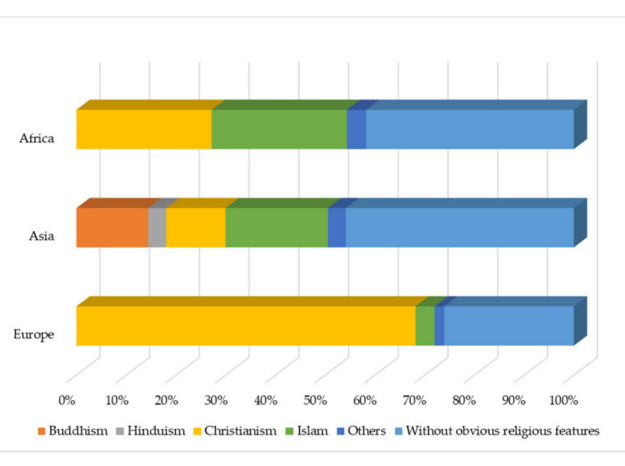

(b)

Figure 5. (a) Distribution of religions in cultural heritage. (b) Distribution of religions in cultural heritage. 


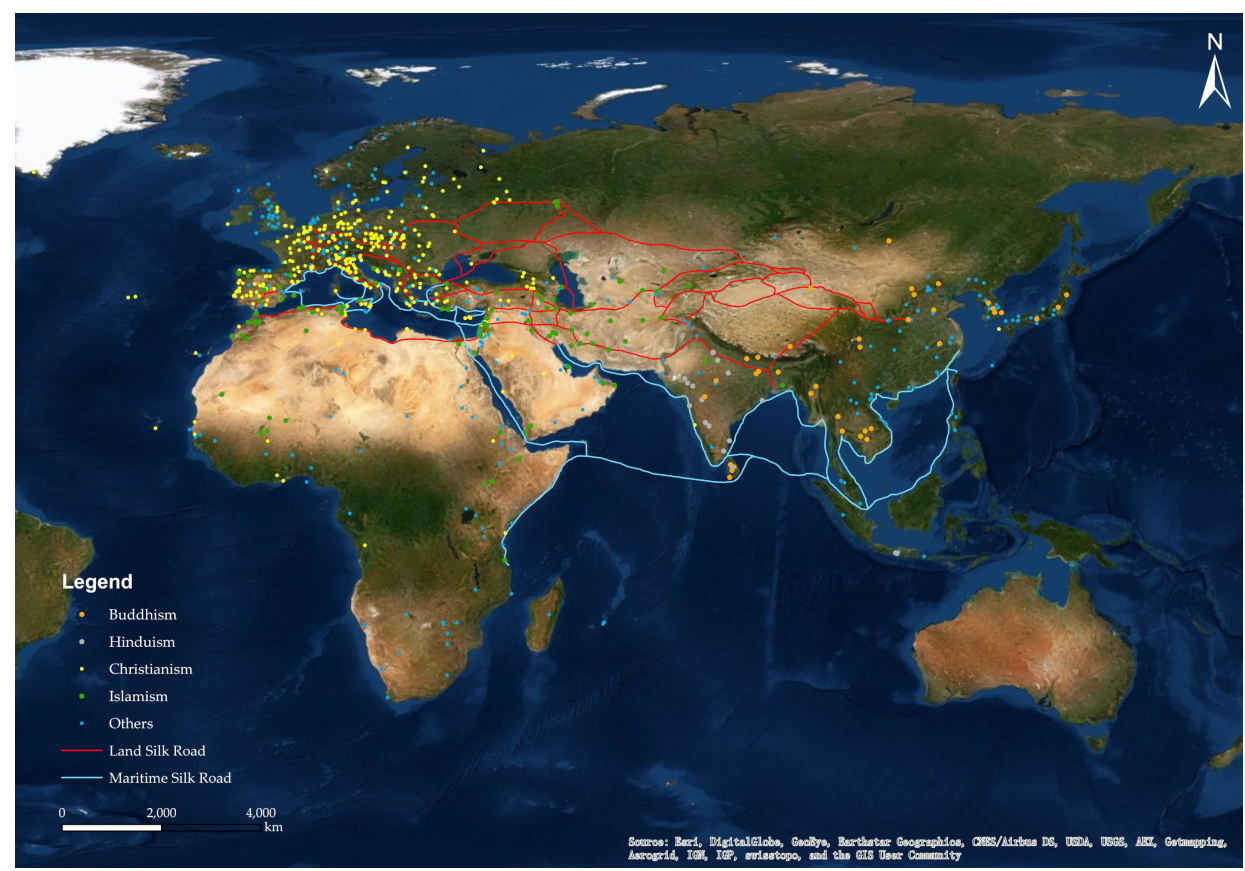

Figure 6. The spatial distribution of religious sites.

\subsection{Criteria Used in Declarations}

The Operational Guidelines for the Implementation of the World Heritage Convention explain six criteria for selection [32]. In our study area, 766 sites consisted of 1877 times items, averaging about 2.45 criteria for each site. In Table 6, criterion IV (to be an outstanding example of a type of building, architectural, or technological ensemble or landscape that illustrates significant stages in human history) is the most frequently used, and criterion $\mathrm{V}$ (to be an outstanding example of a traditional human settlement, land use, or sea use which is representative of a culture or cultures, or human interaction, with the environment, especially when it has become vulnerable under the impact of irreversible change) is the least used. This statement indicates that architecture has the advantage of being included as a part of WCHS. In comparison, it is easy to preserve and has the intuitiveness of conveying culture in criterion IV. Most likely, the frequency of criterion V signifies the lack of highlighted cultural heritage related to the environment of human livelihood activities at intercontinental sites generally.

Table 6. Criteria statistics of site number and the proportion of the criteria in this standard selection, listed criteria in WCHS.

\begin{tabular}{ccc}
\hline Criteria & $\begin{array}{c}\text { Number of Sites } \\
\text { (Ratio in All Sites) }\end{array}$ & $\begin{array}{c}\text { The Proportion of the Criteria in This Standard Selection, } \\
\text { Listed Criteria in WCHS }\end{array}$ \\
\hline I & $223(11.88 \%)$ & $29.11 \%$ \\
II & $396(21.10 \%)$ & $51.70 \%$ \\
III & $405(21.58 \%)$ & $52.87 \%$ \\
IV & $506(26.96 \%)$ & $66.06 \%$ \\
V & $135(7.19 \%)$ & $17.62 \%$ \\
VI & $212(11.29 \%)$ & $27.68 \%$ \\
\hline
\end{tabular}

The difference in the selection criteria of cultural heritage reveals the difference in the core values of cultural heritage among the three continents. The declaration standards reflect the focus of cultural heritage on all the continents, which is not only related to the development of local culture but also has practical guiding significance regarding the application of heritage. From an intercontinental perspective in Figure 7, criterion IV is the most commonly used in Europe, and criterion $\mathrm{V}$ is the least used, which indicates that archi- 
tectural art is an important carrier of European civilization, and historical buildings or architectural complexes have been rooted in the vast European region as cultural/civilization symbols. Criterion III is the most frequently employed in Asia, while criterion V is the least used. As one of the important birthplaces of traditional civilizations, Asia has an edge in terms of the cultivation and development of various civilizations. Criterion III is the most commonly used one in Africa, and criterion I is the least frequent. This finding suggests that Africa is more relevant to human civilization or cultural traditions and has a rich historical background, but what still needs to be enriched is the cultural heritage of art.

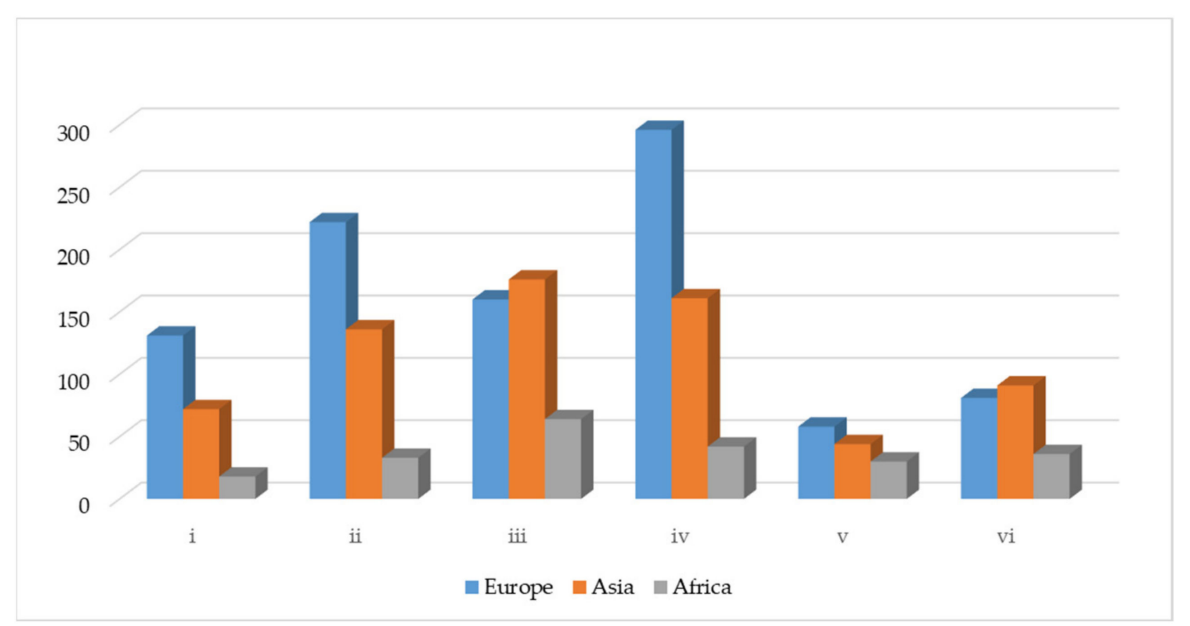

Figure 7. Distribution of the listed criteria in WCHS.

The applicable criteria reflect the focus of cultural heritage on all the continents, which is not only related to the development of local culture but also has a practical guiding significance in the application of WCHS.

\subsection{World Cultural Heritage (WCHS) in Danger and Cultural and Natural Mixed World Heritage}

In our study area, since the particular essential property of these two types need to be more targeted and protected, mixed heritage and endangered heritage should be emphasized.

\subsubsection{Mixed Heritage}

Mixed heritage refers to a type of WH with outstanding universal values of both culture and nature. Its concept has been officially announced by the Operational Guidelines for the Implementation of the World Heritage Convention. As of 2019, there are 23 mixed heritage sites in our study area. The distribution of mixed heritage sites is displayed in Figure 8. The overall spatial distribution is relatively even, including 10 sites in Asia, seven in Europe, and six in Africa, distributed relatively evenly in coastal and inland areas. The landscape material types are mainly composed of soil and rock or brick, and more than half of the sites have a long history before the Common Era. The applicable standards have their respective focuses. In terms of the cultural and natural heritage listed standards, criteria III has been used the most frequently. Overall, the cognition of the value of dual heritage features dynamic changes. 


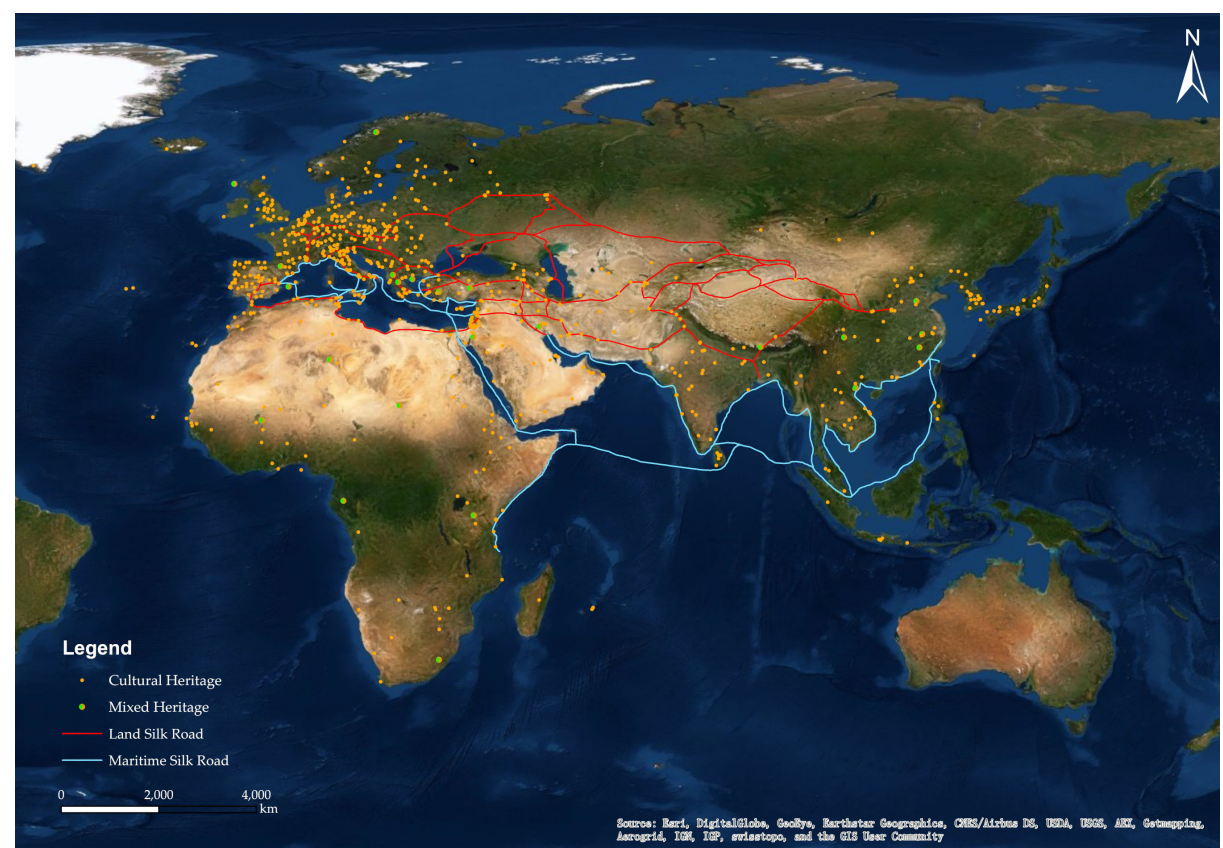

Figure 8. Spatial distribution map of mixed heritage sites.

For mixed heritage, it is difficult to maintain balance in both cultural and natural attributes requiring protection. Sometimes the natural landscape will seriously affect the protection of the cultural landscape. For example, to protect heritage buildings, some vegetation must be removed since the plant roots will continue to threaten the stability of the building or even cause it to crack or collapse, but to some extent, the overall beauty of the site will be diminished. Therefore, while protecting such sites, more attention should be paid to the coordinated development of the dual attributes of culture and nature. Figure 8 illustrates that the distribution of dual heritage has no obvious latitude characteristics, so in the process of protection, measures should be taken according to local conditions and the overall protection, as compatible with the specific geographic environment.

\subsubsection{Endangered Heritage Sites}

Since 1994, to protect cultural heritage, UNESCO has strengthened the monitoring of cultural heritage, listed heritage sites with serious problems on the World Heritage List in Danger and urged countries where heritage sites are located to take measures to restore and protect cultural heritage. In 2019, there were 31 endangered heritages (see Figure 9) in Asia, Africa, and Europe. Based on the background information of these heritage sites, the types of threats were divided into natural factors, including floods, earthquakes, volcano hazards, landslides, as well as human factors, including war, robbery, fire, urbanization, etc.

After a comprehensive analysis, we discovered that only four heritage sites are endangered, primarily due to natural factors, with the remainder subject to human factors. Endangered world cultural heritage, accounted for nearly $90 \%$ of the total number of endangered properties. Among these endangered properties due to human factors, 17 properties are endangered mainly due to war-over $60 \%$ of the number of endangered properties due to human factors. Clearly, human factors are the main factor for these cultural heritage sites to be listed as endangered. Combined with the image map, one can see that these endangered cultural heritage sites are unevenly distributed, mainly in Central Asia, West Asia, North Africa, East Africa, West Africa, and some parts of Europe. Among them, natural factors such as floods, earthquakes, etc. are listed, mainly in North Africa and West Africa, as well as a few local human activities, long-term exposure to nature, and vulnerability to natural conditions, such as floods. Therefore, these sites need to be reinforced, and damming or other physical restoration measures should be considered. The cultural heritage sites listed as endangered due to human factors are predominantly located in 
West Asia, North Africa, Central Asia, and parts of Europe. Among them, the cultural heritage sites threatened by war are mainly on the east coast of the Mediterranean Sea in West Asia and the Mediterranean Sea in North Africa. The southern coast and Central Asia, Afghanistan, and Montenegro in Southern Europe, as well as the east coast of West Asia and the Mediterranean, are relatively dense, or they have a certain relationship with the long-term conflicts of the three religions of Christianity, Islam, and Judaism, as well as wars caused by instability. The stone materials at those sites strengthen and protect them. Furthermore, urbanization has also put some famous heritage sites on the verge of threats. For sites endangered by urban construction, the relationship between urban construction and heritage protection can be properly handled. The construction of tall buildings and factories should be as far away as possible from important heritage sites left behind in cities. Moreover, heritage sites in certain jungles of Africa are prone to the threat of fire caused by climate change. Therefore, effective protection measures must be taken for these endangered cultural heritages that are threatened by natural and human factors. Remote sensing provides a crucial avenue for developing a global transparent early-warning system before irreversible damage to world heritage takes place [33]. As far as cultural heritage managers are concerned, armed conflicts may not be easy to intervene in, but disputed technologies can be corrected in the first place, so it is necessary to establish an early warning mechanism for key areas.

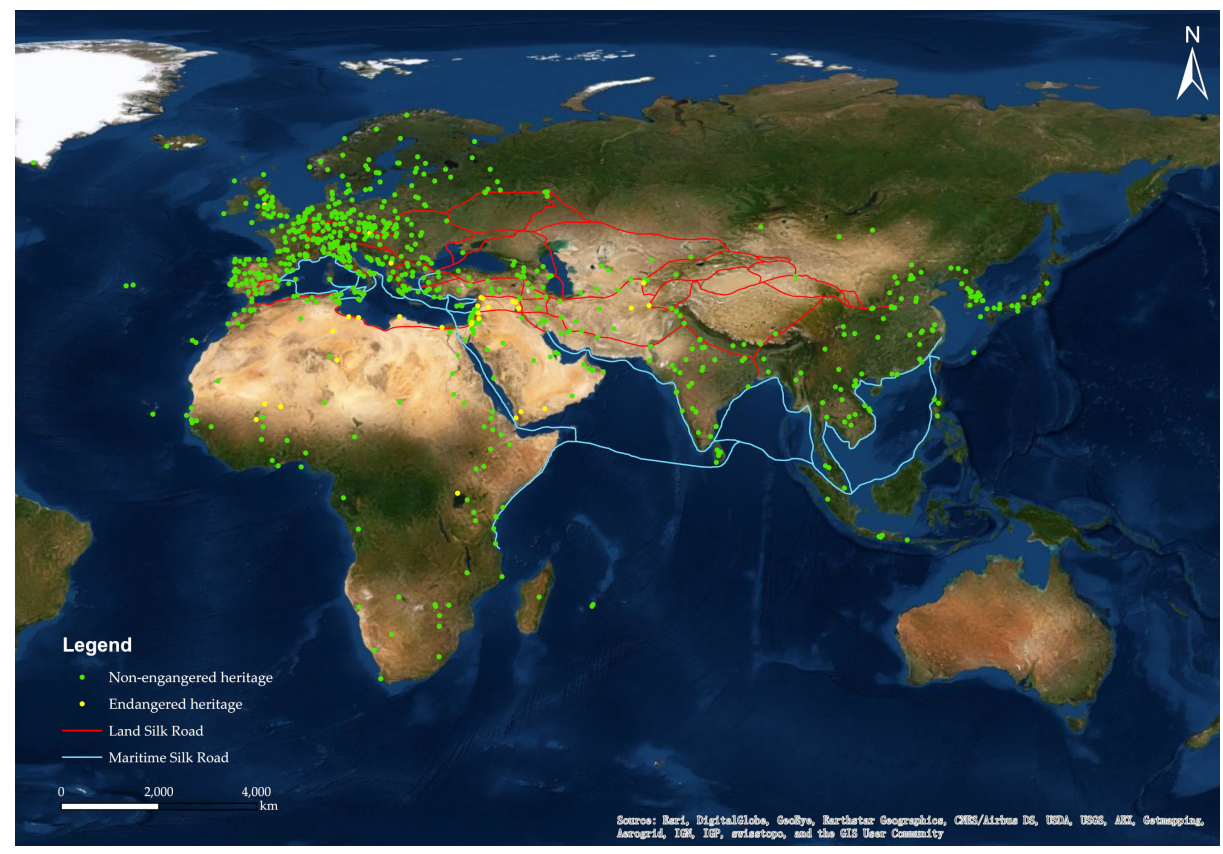

Figure 9. Spatial distribution map of endangered cultural heritage sites.

\subsection{Spatial Distribution of Capital Investment}

The protection of $\mathrm{WH}$ certainly requires financial support and the protection of $\mathrm{WH}$ is closely related to the level of economic development of a country or a region. GDP per capita and GDP for the area of the country indicate the size of the financial capacity that can be invested in cultural heritage protection. The economic and cultural development of the LSR and MSR initiative contributes to the opportunities of countries and neighboring countries along the route. From the perspective of capital investment capacity, we can demonstrate its potential protection capabilities for cultural resources, and we can illustrate the advanced nature of the country's overall development level, including the maturity of cultural heritage protection awareness and scientific-technological methods. As seen in Figure 10, both the per capita and unit area of the GDP in Western Europe are the highest, followed by some other regions of Central Europe, Southern Europe, Northern Europe, and East Asia. However, there are still some low-GDP regions, such as Eastern Europe, 
Central Asia, East Africa, and West Africa, which possess a considerable number of WH sites. The investment in protection will come under great pressure due to the lack of education, science, and technology. This situation needs more attention. The figure below shows that Europe has the most cultural heritage sites, followed by Asia, and Africa has the least. The African continent is not only an important witness to the evolutionary history of humankind, but also an important cradle of ancient civilizations in the world. Limited by its level of economic development, there are a relatively small number of cultural heritage sites in this region, but the region also has more potential cultural heritage locations. As the birthplace of humanity, the protection of its rich cultural heritage resources is directly limited by economic development. In other words, many sites with OUV potential in this region are facing the threats of gradual disappearing, almost unprotected. Encouraging Africa, Central Asia, and other regions with rich cultural resources, but an underdeveloped economy to declare for WCHS, not only can provide an opportunity for the protection of cultural heritage, but also can create more job opportunities for the region through tourism development and utilization. Furthermore, this will improve the economic situation of the region directly. Therefore, it is necessary to vigorously help underdeveloped countries, as well as to provide assistance in protection via investments, protection methods, technical support, and professional development training for managers. Moreover, these countries should be encouraged to declare WH sites to increase the amount of WCHS in underdeveloped regions. For economically developed areas, the approach should mainly be based on the perspective of heritage protection, sharing advanced cultural heritage protection methods and technologies, further enhancing the concept of cultural heritage protection, and realizing the protection of existing cultural heritage sites, while gradually expanding the number of cultural heritage sites.

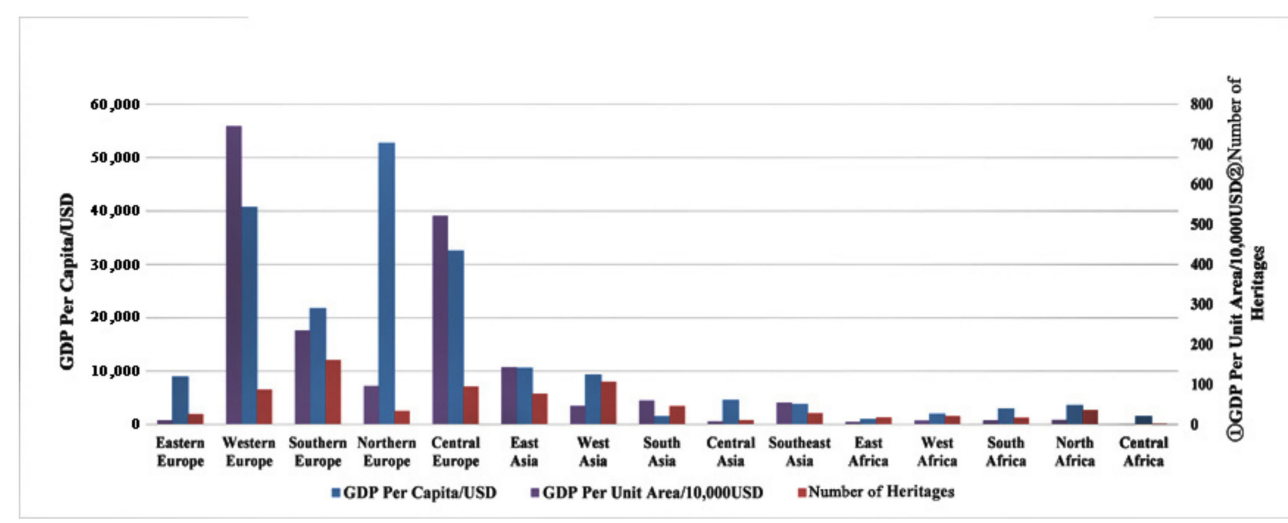

Figure 10. Statistics graph of gross domestic product (GDP) per capita, GDP per unit area, and the number of cultural heritage sites.

Admittedly, tourism and cultural heritage protection have always been controversial topics. On the one hand, as a stakeholder, promote the economic benefits brought by tourism and pursue the maximum economic benefits, on the other hand, due to management limitations, blindly pursue economic benefits regardless of tourism environment bearing capacity, especially in developing countries. Due to the restriction of mass awareness and management technology level, several WCHS have been destroyed [34-36]. As the sustainable development of cultural heritage is proposed, more and more scholars and policymakers are paying attention to cultural heritage sustainability [30,37-39]. Many measures are recommended, such as in the preliminary planning, related researches should be conducted to evaluate the impact of tourism and make reasonable planning, and improve the management level and actively monitor heritage sites avoiding harming the WCHS caused by tourism. 


\subsection{Risk Assessment of the Cultural Heritage Sites}

WH sites are facing potential threats from both human and natural factors [19,40]. The possible natural environmental factors that affect these sites include soil erosion, landslides, floods, and sea-level rise. Human activities such as war and tourism pressure can also lead to the degradation and destruction of heritage sites. Considering all the sites, we identified the risks that heritage sites face, as explained below.

\subsubsection{Risk Assessment of Cultural Heritage Sites under the Influence of Natural Factors} Volcano Hazard Risk Assessment

There are 766 WCHS sites in the LSR and MSR region, of which $14(1.83 \%)$ cultural heritage sites have a high volcanic disaster risk, $22(2.87 \%)$ have a medium volcanic disaster risk, and $730(95.3 \%)$ have a low risk of volcanic disasters. The main distribution is shown in Figure 11. Among the countries concerned, Japan accounts for the largest proportion of high-risk volcanic disaster sites. Among all the medium and high-risk sites, Japan, Italy, and Indonesia have more than half of the heritage sites. In particular, these three countries should offer key policy guidance and technical support for volcanic disaster monitoring and protection. Volcanic risk is an important challenge for the protection of cultural heritage. For example, ash from the Merapi volcano in Indonesia in 2018 had a serious impact on Borobudur Temple [41]. We should start from the initial disasters threatening WCHS in areas with a high risk of volcanic activity, focus on monitoring and preventive protection of cultural heritage.

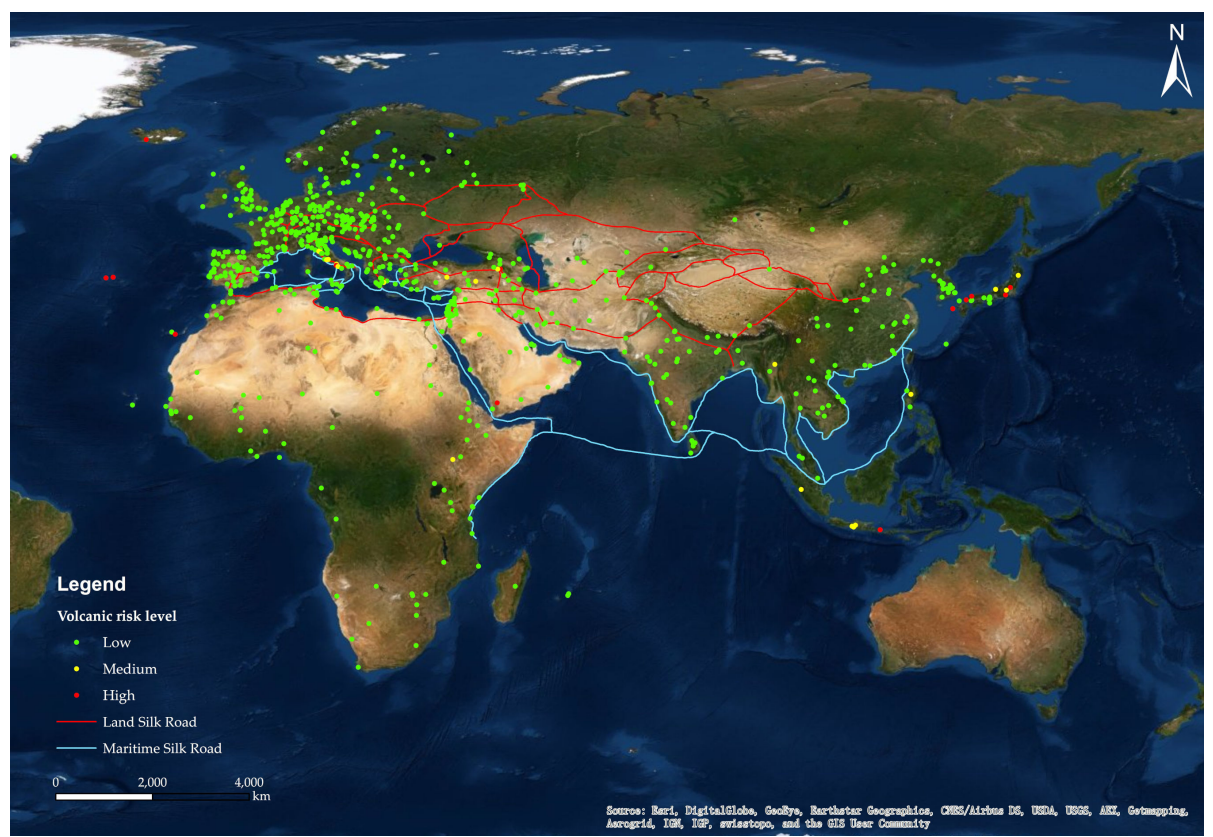

Figure 11. Spatial distribution of the volcano hazard risk level.

\section{Landslide Hazard Risk Assessment}

In recent years, the acceleration of economic construction, large-scale mining, land reclamation, destruction of vegetation and ecological balance, and the trend of warm, wet, and rainy climates have also led to frequent natural disasters, including landslide disasters in a stage of high incidence. There are 766 WCHS sites in the LSR and MSR region, of which $53(6.92 \%)$ cultural heritage sites have a high risk of landslide disasters, $64(8.36 \%)$ have a high risk, 153 (19.97\%) have a moderate risk, 263 (34.33\%) have a low risk, and $233(30.42 \%)$ have a very low risk. Among these sites, the age distribution of high-risk sites of landslide disasters is relatively even, spatially distributed mainly along the coast (Figure 12), and the Mediterranean coast is relatively dense. In terms of material types, stone heritage materials have the largest number (29), followed by earth and stone (19). One can see that buildings 
and complexes face a greater threat of landslides. As landslides are secondary disasters, we should start from the factors that cause such disasters and strengthen the supervision of environmental factors, such as precipitation, surrounding rocks, earthquakes, etc.

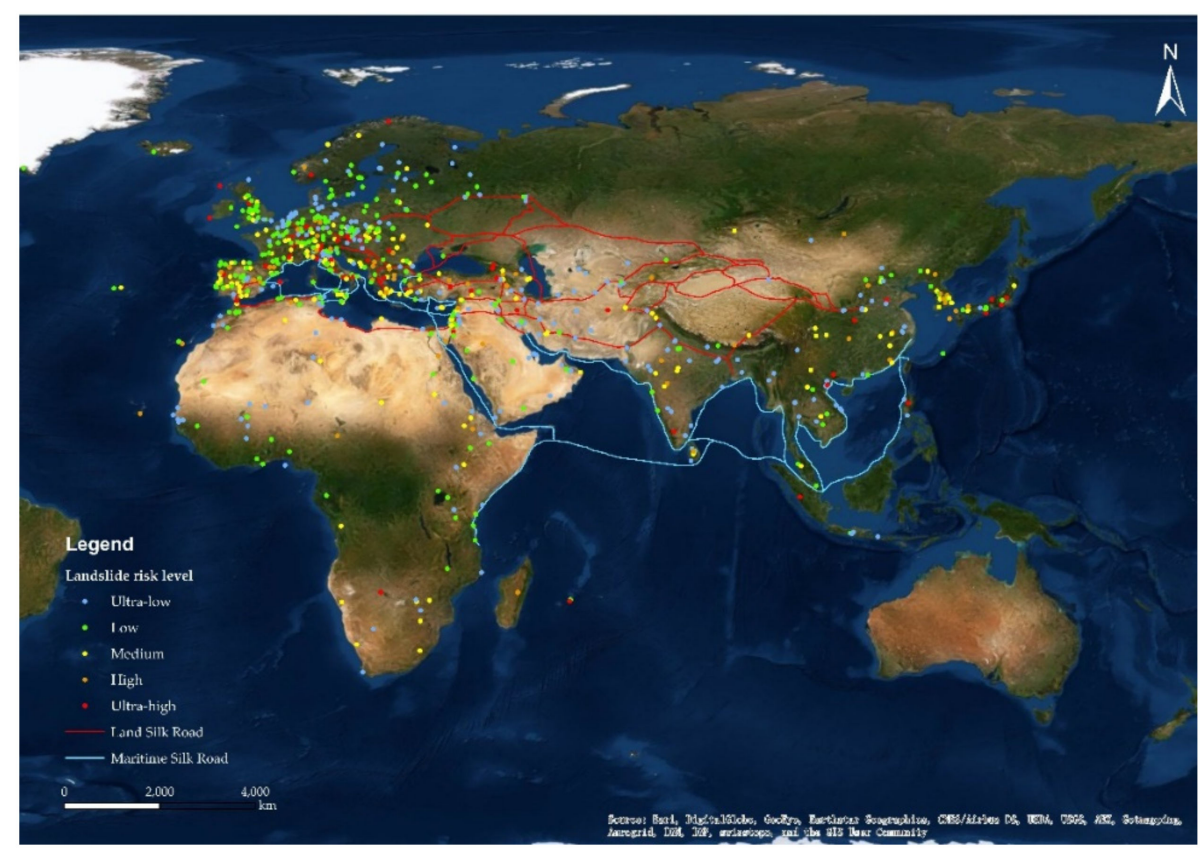

Figure 12. Spatial distribution of the landslide risk level.

Seismic Disasters Hazard Risk Assessment

There are 766 WCHS sites in the LSR and MSR region, of which two $(0.26 \%)$ have a high risk of earthquake disasters, all located in the earthquake zone of Japan; $62(8.09 \%)$ cultural heritage sites have a high risk. Most of the earthquake disaster risks are densely distributed along the Aegean Sea (see Figure 13). Among the high-risk areas, five sites are natural and cultural dual heritage sites, and these five should be more focused on regarding monitoring and protection; $190(24.80 \%)$ cultural heritage sites have a moderate earthquake disaster risk, $186(24.28 \%)$ have a low risk, and $326(42.56 \%)$ have a very low risk. Earthquakes are extremely random and difficult to predict, which leaves hidden dangers regarding the protection of cultural heritage to a certain extent, but earthquakes are extremely destructive. Therefore, earthquake prediction is still necessary for the process of cultural heritage protection, especially in areas above medium risk. We should also implement earthquakeproofing measures, such as strengthening buildings, adding earthquake-resistant firefighting systems, etc.

Earthquakes, landslides, and volcanoes are identified as the main geological disasters faced at WCHS sites, based on a statistical analysis of the cultural heritage of the LSR and MSR affected by natural disasters in the past (where the number of medium risks accounts for less than 10\%). For the cultural heritage sites in the LSR and MSR regions, the study results suggest that the greatest impact of the geological disaster risk is caused by earthquakes and landslides. A total of 233 sites in low-risk areas (30\%), 387 sites in medium-risk areas (51\%), and 145 sites in high-risk areas (19\%) were noted. See Figure 14 for the distribution map. Among the 145 sites, four are endangered heritage sites, and 11 are mixed heritage sites. The materials are mainly stone and brick and stone-earthen types (76 and 35, respectively). On the whole, WCHS sites with high geological hazard risk are mainly distributed in Japan and the coastal areas of the northwestern Mediterranean. In addition, among all the cultural heritage sites in the study area, the Shrines and Temples of Nikko is a site at high risk of all these three geological disasters. The protection of this site requires more refined monitoring and protection for its architectural structures or the environment, as it is a stone-wooden structure. 


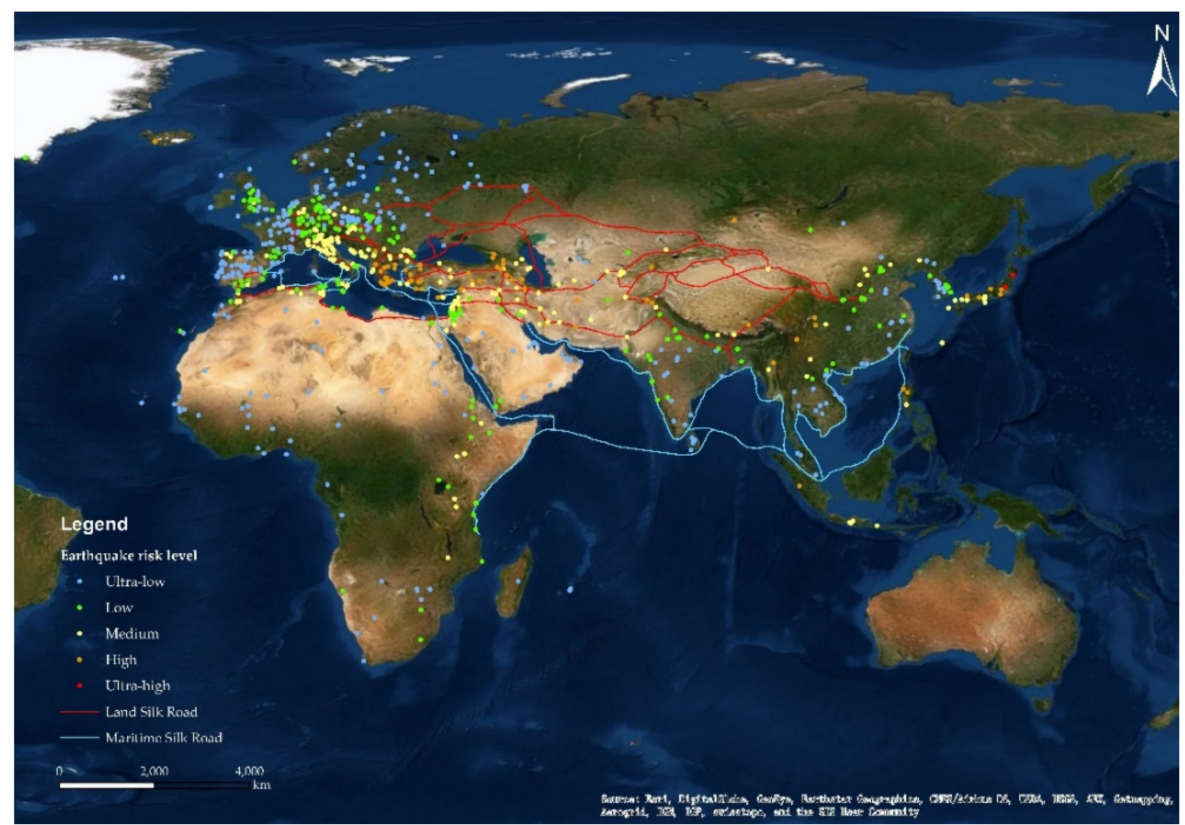

Figure 13. Spatial distribution of the earthquake hazard risk level.

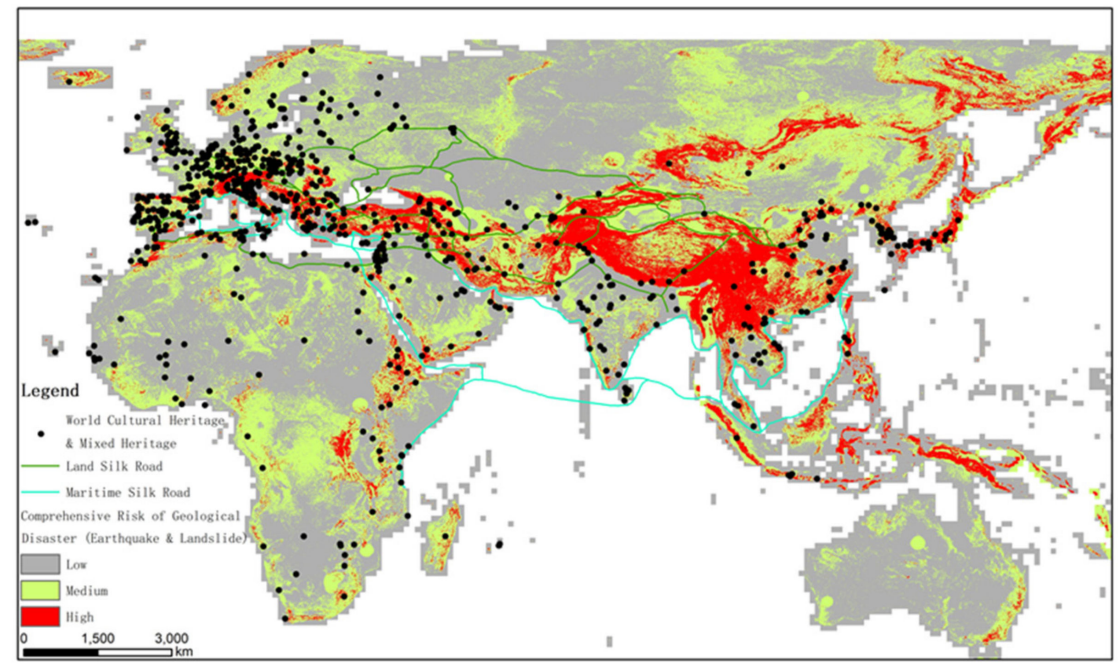

Figure 14. Comprehensive Assessment Mapassessment map of Geological Disaster Riskgeological disaster risk of WCHS in the Beltbelt and Road Initiativeroad initiative.

At present, there is also a lack of relevant guidebooks, policies, and regulations for dealing with natural disasters on a global scale [42]. Researchers in various fields need to cooperate to study the problem of cultural heritage disaster prevention, but the protection of cultural heritage sites from natural disasters occurs country by country. From the perspective of global WCHS, it is possible to establish normative and guiding regulations in response to the Regulations for the Protection of World Heritage in Response to Natural Disasters such as Earthquakes and Floods.

\subsubsection{Risk Assessment of Cultural Heritage under the Influence of Human Factors}

Urbanization refers to the process of population migration and gathering from scattered rural areas dominated by agriculture to urban areas dominated by the industry and services. This phenomenon is the most significant process of human activities since the 20th century. According to data from the United Nations, the proportion of the global urban population increased from less than $30 \%$ in 1950 to $55 \%$ in 2018 . It is estimated that, by 2050 , this proportion will reach $68 \%$, and nearly $90 \%$ of urban population growth 
will be concentrated in Asia and Africa. Global urbanization trends are closely related to sustainable development [43]. The urbanization process has changed land cover and use, transportation, landscapes, and the environment of cities, which have directly or indirectly affected the WH sites [44].

We selected 79 cities along the LSR and MSR and cultural heritage sites near urban settlements. By calculating the UII of urbanization intensity in 2000 and 2015, according to the UII value of each heritage site in 2000 and 2015, the change rate was calculated, and 79 heritage sites in the LSR and MSR initiative were classified. Four types of cultural heritage sites exist: Extremely low change $(<0.14)$, low change $(0.14-0.39)$, medium change (0.39-1.37), and high change ( $>1.37)$. A total of seven heritage sites in the LSR and MSR initiative were identified as having high and medium UII value changes. Among them, there are five in China, one in Nepal, and one in India. Figure 15 shows the specific grade distribution.

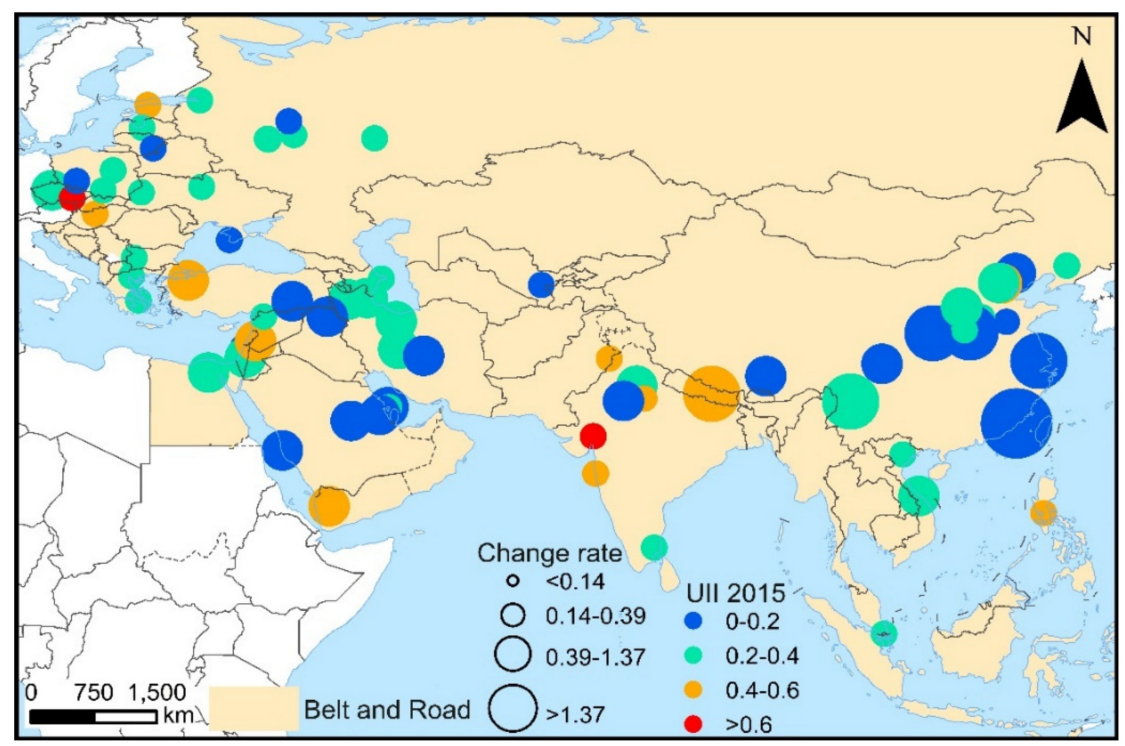

Figure 15. Changes in the urbanization intensity of cultural heritage sites along the land silk road (LSR) and maritime silk road (MSR) initiative from 2000 to 2015.

A total of seven heritage sites in the LSR and MSR regions have been identified as having high and medium UII changes, including five in China, one in Nepal, and one in India. Since the early 1990s, China has experienced unprecedented urban expansion and rapid socioeconomic development. We found that, from 2000 to 2015, the rate of change of UII in the buffer zone-such as Gulangyu Island in China, classical gardens in Suzhou, historical monuments in Dengfeng, the Mausoleum of the First Emperor of Qin, and the ancient city of Lijiang - was relatively high. Based on the analysis of high-resolution remote sensing images and socioeconomic statistical data during the same period, these areas have experienced significant population gathering, as well as the expansion of built-up areas and transportation facilities.

At the 41st UNESCO World Heritage Conference in July 2017, the historic national community of Gulangyu Island in Xiamen, China, was officially included in the World Cultural Heritage List. Later, in 2019, the Chinese government introduced measures, including classification and classification protection, to strictly control the tourist capacity of core scenic spots, prohibit new development and construction and construction engineering operations, and strengthen the protection of historical buildings and cultural relics to ensure the sustainability of scenic spots and their development [45]. Based on big data from the earth and UII data, the dynamic monitoring of the development of cities around cultural heritage sites, as well as the timely detection and prevention of possible damage to heritage sites by human activities, will help formulate and strengthen heritage protection policies. 
With the acquisition of satellite data with improved characteristics, such as Sentinel 1/2 satellite data, GaoFen satellite data, and NPP-VIIRS night light image data, it is possible to create images with higher temporal and spatial resolution and accuracy in future research. Intensity assessment data. This study only confirms the evaluation results of the urbanization intensity of heritage sites with high-resolution satellite images. In the future, more abundant statistical data and ground observations will be available for verification of the evaluation results. Furthermore, the evaluation of the intensity of the urbanization of heritage sites can consider more factors, such as tourism and transportation.

\section{Conclusions and Perspectives}

\subsection{Conclusions}

The distribution characteristics of WH are gradually formed. Although the criteria for inclusion in the World Heritage List setting by the World Heritage Committee are objective and reliable, different countries have different degrees of cherished and protected heritage sites, public awareness, and enthusiasm for participating in international actions. These differences make the following spatial-temporal distribution of WCHS features.

From a large intercontinental scale, the characteristics of the temporal and spatial structure show that the WCH sites have a high degree of chronological concentration. The spatial distribution is densely distributed along the Mediterranean coast in Europe, and Asia and Africa are relatively even. The main distribution direction of WCH sites on the three continents is east-west. In terms of time, there is some perceptible difference in the number of world cultural heritages in different historical stages. From the Neolithic Age to the 8th century AD, the ruins containing the budding period of human civilization are a relatively small amount, and the 16th century, which is compensated for by cultural activity, has the largest number. The characteristics of time and space will help us understand the territoriality features and trends of WCH more comprehensively.

For cultural characteristics of WCH in Asia, Africa, and Europe, the top three in the number of civilizations are ancient Roman civilization, Chinese civilization, and Arab civilization. The amount of world cultural heritage in these civilizations also reflects the key role these civilizations have played in human history. Religious characteristics also show the tendency of concentration of Christianity, while Islam has the widest radiation, while cultural heritage such as Buddhism and Hinduism is the most concentrated. The distribution of religions also reflects the spread of different cultural values. The numbers of cultural heritages of different civilizations, religions, and criteria are also interesting clues to show cultural diversity.

From the cultural heritage perspective of preserving, through the analysis of the material types, capital investment, and risk assessment of cultural heritage, it can be seen that the intercontinental differences in indicators such as the material types and GDP per capita per unit of land are large in Europe, Asia, and Africa. In short, the level of regional development restricts the protection and utilization of cultural heritage. In the future, in WH declarations, attention should be paid to the imbalance in regional development limitations, WCH management, and preservation in different regions and included in the global WCH system regarding planning and comprehensive protection. For a more targeted protected mixed and endangered heritage, we are from the standpoint of the realistic situation working with the higher frequency and fine monitoring. Through the comprehensive geological disaster risk assessment, the proportion of high-risk and medium-risk cultural heritage is about $70 \%$, this suggests that more targeted monitoring, early warning, and emergency response capacity should be taken into regulations. In addition, establishing a more scientific, comprehensive, multi-index, large-scale risk assessment system for WCH sites appears indispensable.

\subsection{Perspectives}

The Silk Road is a trade channel linking East Asia and Central Asia, leading to South Asia, West Asia, and Europe and North Africa. It has witnessed the process of 
human history from isolation and isolation of various nations and countries to communication and integration. Whether on land or at sea, through the Silk Road this important channel, the East and West products, science and technology, culture, religion, etc. can be spread and spread, which has painted a rich and colorful history of human civilization. The cultural heritage sites along the MSR and LSR regions are evidence of historic human activities in Asia, Europe, and Africa. They are also vivid cases and teaching materials to help us learn and understand how to open our commerce, trade, and scientific and technological exchanges, as well as public communication. In addition, how to apply for WCHS recognition and protect these sites in a targeted way among continents and countries will require further study. Moreover, WCHS should be declared and protected in a planned way among continents and countries, which will become the focus issue of heritage protection work.

The world heritage sites of the LSR and MSR regions have problems in terms of declaration and approval due to inadequate protection actions and unbalanced protection capacities. Thus, the following countermeasures are proposed.

In technology, on one side, it is necessary to establish a comprehensive WHC database, and conduct multi-scale synthetical researches. Although a lot of information already exists on the websites of UNESCO, there are few characteristic statistics and summaries. Only with the overall background characteristics of in-depth summary and understanding of sites, can we better provide effective reference information for cultural heritage managers to make decisions. On the other side, the advantages of digital technology including 3D, geographic information system (GIS), and remote sensing (RS) could be fully utilized. In the 21st century, against the background of the next generation of digital earth studies, spatial information technology integrating RS detection, GIS spatial analysis, SNAP, virtual reality, and other spatial information detection technologies and spatial analysis methods appears in the field of cultural heritage, which can greatly promote the development of management and protection of cultural heritage.

At the policy level, firstly, it is essential to figure out the characteristics and the potential of important cultural and natural heritage sites on a big scale. UNESCO should strive for top-level design and promote the declaration of relevant countries in a planned and step-by-step way. At present, UNESCO has leading voices in the formulation of cultural heritage protection norms and related proposals. As the sustainable development of cultural heritage is proposed, the challenges of uneven regional development, globalization, and its effect on cultural diversity all require more comprehensive background knowledge to understand and protect world cultural heritage. In the next place, the declaration of WCH sites in Africa, Central Asia, and other regions should be positively supported. Compared with the economically developed regions of Europe, these regions contain rich cultural resources, but also face the threat of a dying out limited protection. WH is the commonwealth of all humankind. Anything that conforms to the outstanding universal value (OUV) and the preservation status conforms to authenticity and integrity, and such sites should be declared to obtain the common attention and protection of the world-not just that of the host country. To garner help and support for WH protection, investments, technologies, and training sessions should be provided for countries and regions which are undeveloped or lacking experience in heritage management. In this case, policymakers should negotiate with the countries involved and work together to achieve the SDG 11.4 goal with the coordination of UNESCO. Lastly, to strengthen experience exchange in risk and protection management, and promote the sustainable development of WHC by managers. UNESCO should propose more potential risk assessments and countermeasures. Here, establishing a level-to-level risk administration mechanism, and conducting more targeted monitoring mechanisms and protection measures for various risk levels of WHC sites is suggested. Specifically, in the face of man-made impacts such as tourism and urbanization, correct evaluation and implementation measures should be guided in the planning. 
Author Contributions: Conceptualization, Y.Y., X.W., L.L. (Linlin Lu), C.L., Q.W., H.R., S.Y., R.S., L.L. (Lei Luo), and K.W.; data curation, Y.Y., X.W., (L.L.) Linlin Lu, C.L., Q.W., H.R., S.Y., R.S., L.L. (Lei Luo), and K.W.; formal analysis, Y.Y., X.W., L.L. (Linlin Lu), C.L., Q.W., H.R., S.Y., R.S., L.L. (Lei Luo), and K.W.; funding acquisition, Y.Y., X.W., L.L. (Linlin Lu), C.L., Q.W., H.R., S.Y., R.S., L.L. (Lei Luo), and K.W.; investigation, Y.Y., X.W., L.L. (Linlin Lu), C.L., Q.W., H.R., S.Y., R.S., and K.W.; methodology, Y.Y., X.W., L.L. (Linlin Lu), C.L., Q.W., H.R., S.Y., R.S., L.L. (Lei Luo), and K.W.; project administration, Y.Y., X.W., L.L. (Linlin Lu), Q.W., and H.R.; resources, Y.Y., X.W., L.L. (Linlin Lu), C.L., Q.W., H.R., S.Y., R.S., L.L. (Lei Luo), and K.W.; software, Y.Y., L.L. (Linlin Lu), C.L., Q.W., H.R., S.Y., R.S., and K.W.; supervision, Y.Y., X.W., L.L. (Linlin Lu), and Q.W.; validation, Y.Y., X.W., L.L. (Linlin Lu), C.L., Q.W., H.R., S.Y., R.S., L.L. (Lei Luo), and K.W.; visualization, Y.Y., C.L., Q.W., H.R., S.Y., R.S., L.L. (Lei Luo), and K.W.; writing-original draft, Y.Y., X.W., L.L. (Linlin Lu), C.L., Q.W., H.R., S.Y., R.S., and K.W.; writing-review and editing, Y.Y., X.W., L.L. (Linlin Lu), Q.W., H.R., S.Y., L.L. (Lei Luo), and K.W. All authors have read and agreed to the published version of the manuscript.

Funding: This research was funded by The Strategic Priority Research Program of the Chinese Academy of Sciences, grant number XDA19030500.

Data Availability Statement: Some or all data, models, or code generated or used during the study are available from the corresponding author by request. (List items).

Acknowledgments: The author is grateful to the editor and anonymous reviewers for spending their valuable time on constructive comments and suggestions that improved the quality of the manuscript considerably.

Conflicts of Interest: The authors declare no conflict of interest. The funders had no role in the design of the study; in the collection, analyses, or interpretation of data; in the writing of the manuscript, or in the decision to publish the results.

\section{References}

1. Meskell, L. UNESCO's World Heritage Convention at 40 Challenging the Economic and Political Order of International Heritage Conservation. Curr. Anthropol. 2013, 54, 12. [CrossRef]

2. Wang, X.; Ren, H.; Wang, P.; Yang, R.; Luo, L.; Cheng, F. A Preliminary Study on Target 11.4 for UN Sustainable Development Goals. Int. J. Geoheritage Parks 2018, 6, 6. [CrossRef]

3. Target 11.4: Strengthen Efforts to Protect and Safeguard the World's Cultural and Natural Heritage: Indicator 11.4.1. Available online: https:/ / unstats.un.org/sdgs/metadata/ (accessed on 15 December 2020).

4. Wang, J.-J. Flood risk maps to cultural heritage: Measures and process. J. Cult. Herit. 2015, 16, 210-220. [CrossRef]

5. Seyedashrafi, B.; Kloos, M.; Neugebauer, C. Heritage Impact Assessment, beyond an Assessment Tool: A comparative analysis of urban development impact on visual integrity in four UNESCO World Heritage Properties. J. Cult. Herit. 2020. [CrossRef]

6. Caust, J.; Vecco, M. Is UNESCO World Heritage recognition a blessing or burden? Evidence from developing Asian countries. J. Cult. Herit. 2017, 27, 1-9. [CrossRef]

7. Marzeion, B.; Levermann, A. Loss of cultural world heritage and currently inhabited places to sea-level rise. Environ. Res. Lett. 2014, 9. [CrossRef]

8. Landorf, C. Managing for sustainable tourism: A review of six cultural World Heritage Sites. J. Sustain. Tour. 2009, 17, 53-70. [CrossRef]

9. Spezzano, P. Mapping the susceptibility of UNESCO World Cultural Heritage sites in Europe to ambient (outdoor) air pollution. Sci. Total Environ. 2021, 754, 142345. [CrossRef] [PubMed]

10. Pan, Y.; Wang, X.; Guo, R.; Yuan, S. Seismic damage assessment of Nepalese cultural heritage building and seismic retrofit strategies: 25 April 2015 Gorkha (Nepal) earthquake. Eng. Fail. Anal. 2018, 87, 80-95. [CrossRef]

11. Zhuang, X.; Yao, Y.; Li, J. Sociocultural Impacts of Tourism on Residents of World Cultural Heritage Sites in China. Sustainability 2019, 11, 840. [CrossRef]

12. Toivonen, T.; Heikinheimo, V.; Fink, C.; Hausmann, A.; Hiippala, T.; Järv, O.; Tenkanen, H.; Di Minin, E. Social media data for conservation science: A methodological overview. Biol. Conserv. 2019, 233, 298-315. [CrossRef]

13. Chan, K.M.A.; Guerry, A.D.; Balvanera, P.; Klain, S.; Satterfield, T.; Basurto, X.; Bostrom, A.; Chuenpagdee, R.; Gould, R.; Halpern, B.S.; et al. Where are Cultural and Social in Ecosystem Services? A Framework for Constructive Engagement. BioScience 2012, 62, 744-756. [CrossRef]

14. Vlami, V.; Kokkoris, I.P.; Zogaris, S.; Cartalis, C.; Kehayias, G.; Dimopoulos, P. Cultural landscapes and attributes of "culturalness" in protected areas: An exploratory assessment in Greece. Sci. Total Environ. 2017, 595, 229-243. [CrossRef]

15. Holocene Volcano List. Available online: http://volcano.si.edu/list_volcano_holocene.cfm (accessed on 12 September 2020).

16. Modeling and Reporting Landslides. Available online: https://pmm.nasa.gov/applications/global-landslide-model (accessed on 12 September 2020). 
17. GAR 2017 Atlas Risk Data and Software Download Facility. Available online: https://risk.preventionweb.net/ (accessed on 12 September 2020).

18. Pesaresi, M.; Huadong, G.; Blaes, X.; Ehrlich, D.; Ferri, S.; Gueguen, L.; Halkia, M.; Kauffmann, M.; Kemper, T.; Lu, L.; et al. A global human settlement layer from optical HR/VHR rs data: Concept and first results. IEEE J. Sel. Top. Appl. Earth Obs. Remote Sens. 2013, 6, 2102-2131. [CrossRef]

19. Stevens, F.R.; Gaughan, A.E.; Linard, C.; Tatem, A.J. Disaggregating census data for population mapping using random forests with remotely-sensed and ancillary data. PLoS ONE 2015, 10, e0107042. [CrossRef] [PubMed]

20. Li, Q.; Lu, L.; Weng, Q.; Xie, Y.; Guo, H. Monitoring urban dynamics in the southeast U.S.A. using time-series DMSP/OLS nightlight imagery. Remote Sens. 2016, 8, 578. [CrossRef]

21. IMF Data. Available online: https://www.imf.org/en/Data (accessed on 12 December 2020).

22. Wirilander, H. Preventive Conservation: A Key Method to Ensure Cultural Heritage's Authenticity and Integrity in Preservation Process. e-Conserv. Mag. 2012, 5, 164-176.

23. Agapiou, A.; Lysandrou, V.; Alexakis, D.D.; Themistocleous, K.; Cuca, B.; Argyriou, A.; Sarris, A.; Hadjimitsis, D.G. Cultural heritage management and monitoring using remote sensing data and GIS: The case study of Paphos area, Cyprus. Comput. Environ. Urban Syst. 2015, 54, 230-239. [CrossRef]

24. Chen, F.; You, J.; Tang, P.; Zhou, W.; Masini, N.; Lasaponara, R. Unique performance of spaceborne SAR remote sensing in cultural heritage applications: Overviews and perspectives. Archaeol. Prospect. 2018, 25, 71-79. [CrossRef]

25. Chen, F.; Guo, H.; Ma, P.; Lin, H.; Wang, C.; Ishwaran, N.; Hang, P. Radar interferometry offers new insights into threats to the Angkor site. Sci. Adv. 2017, 3, e1601284. [CrossRef]

26. Moise, C.; Dana Negula, I.; Mihalache, C.E.; Lazar, A.M.; Dedulescu, A.L.; Rustoiu, G.T.; Inel, I.C.; Badea, A. Remote Sensing for Cultural Heritage Assessment and Monitoring: The Case Study of Alba Iulia. Sustainability 2021, 13. [CrossRef]

27. Stokes, E.C.; Seto, K.C. Characterizing urban infrastructural transitions for the Sustainable Development Goals using multitemporal land, population, and nighttime light data. Remote Sens. Environ. 2019, 234, 111430. [CrossRef]

28. Lu, L.; Weng, Q.; Guo, H.; Feng, S.; Li, Q. Assessment of urban environmental change using multi-source remote sensing time series (2000-2016): A comparative analysis in selected megacities in Eurasia. Sci. Total Environ. 2019, 684, 567-577. [CrossRef]

29. Wong, L.E. Relocating East and West: UNESCO's Major Project on the Mutual Appreciation of Eastern and Western Cultural Values. J. World Hist. 2008, 18, 26.

30. King, L.M.; Halpenny, E.A. Communicating the World Heritage brand: Visitor awareness of UNESCO's World Heritage symbol and the implications for sites, stakeholders and sustainable management. J. Sustain. Tour. 2014, 22, 768-786. [CrossRef]

31. Matsuura, K. Appendix I UNESCO Universal Declaration on Cultural Diversity UNESCO Universal Declaration on Cultural Diversity. Diogenes 2005, 52, 141-145. [CrossRef]

32. Miller, M.C.; Mumford, L.; Fisher, T. The Culture of Cities; Open Road Media: New York, NY, USA, 2016.

33. Noam Levin, S.A.; Crandall, D.; Kark, S. World Heritage in danger: Big data and remote sensing can help protect sites in conflict zones. Glob. Environ. Chang. 2019, 55, 8.

34. Brattli, T. Managing the Archaeological World Cultural Heritage: Consensus or Rhetoric? Nor. Archaeol. Rev. 2009, 42, 24-39. [CrossRef]

35. Su, M.M.; Wall, G. Chinese Research on World Heritage Tourism. Asia Pac. J. Tour. Res. 2011, 16, 75-88. [CrossRef]

36. Timothy, D.J.; Nyaupane, G.P. Cultural Heritage and Tourism in the Developing World: A Regional Perspective; Taylor \& Francis: Abingdon-on-Thames, UK, 2009.

37. Vecco, M.; Srakar, A. The unbearable sustainability of cultural heritage: An attempt to create an index of cultural heritage sustainability in conflict and war regions. Journal of Cultural Heritage 2018, 33, 293-302. [CrossRef]

38. Tweed, C.; Sutherland, M. Built cultural heritage and sustainable urban development. Landsc. Urban Plan. 2007, 83, 62-69. [CrossRef]

39. UNESCO. Operational Guidelines for the Implementation of the World Heritage Convention; World Heritage Centre: Paris, France, 2019; pp. 3-4.

40. Hadjimitsis, D.; Agapiou, A.; Alexakis, D.; Sarris, A. Exploring natural and anthropogenic risk for cultural heritage in Cyprus using remote sensing and GIS. Int. J. Digit. Earth 2013, 6, 115-142. [CrossRef]

41. Wasowski, J.; Dijkstra, T. Recent Research on Engineering Geology and Geological Engineering. In Proceedings of the 2nd GeoMEast International Congress and Exhibition on Sustainable Civil Infrastructures, Egypt 2018-The Official International Congress of the Soil-Structure Interaction Group in Egypt (SSIGE), Cairo, Egypt, 24-28 November 2018; p. 126.

42. Sari, K.P. A Spatial Study on Risk Analysis of Disasters Caused by Natural Hazards to Cultural Heritage in Indonesia. J. Disaster Mitig. Hist. Cities 2018, 12, 8 .

43. Grimm, N.B.; Faeth, S.H.; Golubiewski, N.E.; Redman, C.L.; Wu, J.; Bai, X.; Briggs, J.M. Global change and the ecology of cities. Science 2008, 319, 756-760. [CrossRef] [PubMed]

44. Agapiou, A.; Alexakis, D.D.; Lysandrou, V.; Sarris, A.; Cuca, B.; Themistocleous, K.; Hadjimitsis, D.G. Impact of urban sprawl to cultural heritage monuments: The case study of Paphos area in Cyprus. J. Cult. Herit. 2015, 16, 671-680. [CrossRef]

45. Mei, Q. Protective Reuse Design for Gulangyu Cultural Heritage. In The Values of Gulangyu World Cultural Heritage; Springer: Singapore, 2020. [CrossRef] 